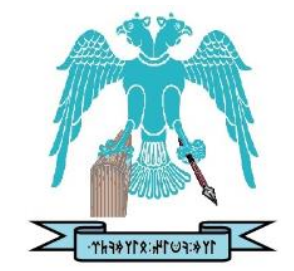

JOURNAL OF ENERGY SYSTEMS

$2020,4(3)$

\title{
Electric vehicle operation modes with reactive power support using SMC in distribution generation
}

\author{
Mendem Premchand ${ }^{(D)}$ \\ Gayatri Vidya Parishad College of Engineering, (Autonomous), Madhurawada Andhra Pradesh, India, \\ mendemchandu36@gmail.com \\ Satish Kumar Gudey \\ Gayatri Vidya Parishad College of Engineering, (Autonomous), Madhurawada Andhra Pradesh, India, \\ satishgudey13@gmail.com
}

\begin{abstract}
In this work, a single phase $120 \mathrm{~V} \mathrm{rms}, 60 \mathrm{~Hz}$ on-board Electric Vehicle (EV) battery charger with capacity $100 \mathrm{Ah}$ for operation in Grid to Vehicle (G2V) and Vehicle to Grid (V2G) with Reactive Power Support using Sliding Mode Controller (SMC) is presented. The controller is chosen for its robustness and steady tracking precision. State space models of G2V and V2G of EV are derived and good stability margins are obtained using frequency response characteristics. SMC is found to be good in tracking the dc voltage in G2V and grid current in V2G with less steady state error. THD in grid current is $0.645 \%$ during G2V and $1.95 \%$ in V2G which are comparatively less than in Proportional plus Integral (PI) and Proportional plus Resonant (PR) controllers. Dynamic nature of SMC is found to be robust during grid frequency variations. It delivers less steady state error of $1.52 \%$ and settling time of $0.1 \mathrm{~s}$ during charging and discharging operations. Phase planes are presented to understand finite convergence of SMC. Reactive power support to the grid operation is presented without affecting the state of charge (SOC) of the battery. Solar based charging circuit is discussed for EV charging. The SOC depicts changeover state from normal to solar charging reaching $100 \%$ within short period. SMC was designed to be robust against bounded perturbations and also guarantee stability and finite convergence. PSCAD v4.6 software is used.
\end{abstract}

Keywords: Battery, Charger, Electric vehicle, Grid to vehicle, Reactive power, Robust, State of charge, Vehicle to grid.

Cite this paper as:

Premchand, M., \& Gudey S.K., Electric vehicle operation modes with reactive power support using SMC in distribution generation. Journal of Energy Systems 2020, 4(3), 96-120, DOI: $10.30521 /$ jes.731845 


\section{INTRODUCTION}

The research and the advancement of the Electric Vehicles (EV) and the charging stations are increasing due to their efficient and eco-friendly transportation [1]. Electric vehicles are categorized as HEV (Hybrid Electric Vehicles), Battery Electric Vehicles (BEV) and PHEV (Plug-in Hybrid Electric Vehicles). The PHEV consists of a battery driven electric motor (BEM) with an internal combustion engine (ICE). It can be plugged for recharge from an external source as well as from its own generator. HEV consists of ICE combined with an electric propulsion system. PHEV's are more popular due to their efficient operation and cost savings. Also, PHEV's serve as support of reactive power to the utility grid during its charging mode. Battery Electric Vehicle also termed as Electric Vehicle (EV) consists of the battery driven electric motor. In EV the battery plays an important role. There are various types of batteries used for EV charging like Lead-acid, Nickel-cadmium and Li-ion batteries. Presently Li-ion batteries are widely accepted for EV due to their high specific energy, good discharging capabilities and long working life. EV chargers are alternatively known as on-board and off-board chargers for unilateral and bilateral power flow. A unilateral charger refers to flow of power to battery from the grid and in bidirectional chargers the reverse happens i.e. from grid to EV battery and EV battery to grid following grid requirements and facility of the EV owner. The on-board chargers are slow chargers, which are used in houses, parking places and the off-board chargers are fast chargers which are used at charging stations [2].

For efficient working of these batteries, controller is very much essential. There are various control methods available for EV in the literature. Few of them are PWM control, phase shift control, PI control, fixed frequency fixed pulse control, predictive control and constant voltage current control methodologies. These methods are used to obtain sinusoidal grid current at unity power factor. These characteristics cannot be obtained during grid unbalance conditions. Also, these require large size filters which accompanies large size and more cost. Few controllers use a notch filter at double the supply frequency and use positive sequence and negative sequence synchronous frames which always cause delay in the input signal and hence slow dynamic response. Even the proportional plus integral (PI) and proportional plus resonant (PR) controllers used in literature have shown that odd harmonic content is more in the grid current waveforms which has adverse effect on the system [2]. The DC harmonic content is more in a PI controller which can be reduced using PR controller. Also, the steady state error and settling time is more, dynamic response is poor and can be improved. It is also important that the battery used in an EV should have good charging and discharging State of Charge (SOC) characteristics for better life, safety and reliability [3].

In [4], conventional sliding mode control (SMC) is used for controlling the output voltage of the DCDC Boost converter and the load current in an ultra-capacitor for EV applications. Adaptive Second order SMC are used to control the gain in the hydrogen Fuel Cell. Efficiency and robustness of SMC are the key characteristics which are obtained in this work. In [5] a SMC is used for battery and/or supercapacitor current regulation and Lyapunov based control method for DC voltage regulation are proposed for an EV. Smooth transition during load changes and good tracking capabilities are achieved using the proposed methods. Modeling is done to obtain a $5^{\text {th }}$ order average model for the Hybrid energy storage system (HESS) system considered. In [6] an estimator-based SMC (ASMC) is proposed for effective tracking of the current in a boost converter-based HESS. The stability of the HESS is achieved for different operating modes. Good battery life and guaranteed stability is proposed with less settling time during load perturbations. SMC proposed in this work provides good tracking of the grid current during V2G and steady DC voltage tracking during G2V, less steady state error, fast dynamic response, less THD and finite time convergence. The SOC for both charging and discharging using bidirectional converters in an EV using SMC can be obtained within short period. 
SMC proposed in this work provides good tracking of the grid current with less steady state error, fast dynamic response and finite time convergence with less Total Harmonic distortion (THD) in the grid current. The SOC of battery for both charging and discharging using a bidirectional converter in an EV using SMC can be obtained within short period. This work focuses on Sliding Mode Control (SMC) implementation for EV to operate in charging and discharging modes using a bidirectional converter. The bidirectional converter considered is a AC/DC H-bridge converter consisting of IGBT switches with their anti-parallel diodes for bidirectional power flow. The DC/DC converter used is bidirectional in nature as well. On-Board charging unit is considered for an EV. A $2.5 \mathrm{~kW}$ to $5 \mathrm{~kW}$ battery charger with $100 \mathrm{Ah}$ capacity is considered in this work. A total capacity of $20 \mathrm{kWh}$ which requires $12-15$ hours is considered. It is found in the literature, most of the researchers have concentrated on the EV charging controllers for vehicle to grid (V2G) and grid to vehicle (G2V) using the conventional PI and PR controllers. In this work, advanced controller like variable structure systems Sliding Mode Controller (SMC) is designed for $\mathrm{G} 2 \mathrm{~V}$ and $\mathrm{V} 2 \mathrm{G}$ operation which can be operated in both modes using the proposed single stage conversion. During the EV charging, converter AC/DC works as a rectifier and two bidirectional DC/DC converter work as step down converter for battery charging to its full capacity. The reverse happens during discharging. For understanding the stability of the system, state space models during G2V and V2G modes are derived with necessary frequency response characteristics. Grid current THD is derived for each case. Tracking of grid current and DC voltage are the control parameters which are controlled effectively for smooth operation of the EV.

The main contributions of this work are summarized as (i) V2G and G2V modes of operation of EV with their mathematical models are simulated with SMC and performance characteristics like dynamic behavior for grid frequency variation, stability, steady state error, THD and settling time are analyzed. (ii) EV charging and discharging modes of operation using a single EV circuit is proposed using SMC and the performance of the controller through phase plane for finite time convergence is presented. (iii) EV reactive power support to the grid is studied. (iv) As an application, solar based EV charging circuit is developed and the SOC of the battery is understood.

Section 2 deals with the sliding mode controller (SMC) for G2V mode of operation, section 3 deals with SMC controller for V2G mode of operation. Section 4 deals with charging and discharging of EV with SMC controller, EV support to the grid through reactive power is also analyzed. Section 5 deals with solar based electric vehicle charging. Finally, conclusions and future scope are presented.

\section{G2V OPERATION USING SMC CONTROLLER}

Sliding mode controller (SMC) is widely utilized for stable tracking of voltage and current in power electronic circuits. Its insensitivity to parametric variations and power converter owing to its variable structure systems have influenced the researchers to use this control mechanism. Also, its robustness is far better than the conventional controllers. The bidirectional converter with SMC controller for grid to vehicle operation is shown in Fig. 1. Here a linear sliding surface $\sigma$ is considered comprising of the dc voltage error and the grid current error. The sliding coefficients are $k_{1}$ and $k_{2}$. The system time constant is obtained by taking $\tau=k_{1} / k_{2}$. For a desired time, response $\tau$, the value of $k_{1}, k_{2}$ can be calculated.

$$
\sigma=k_{1}\left(v_{d c r e f}-v_{d c}\right)+k_{2}\left(i_{\text {gref }}-i_{g}\right)
$$

$\sigma$ is a linear sliding surface given by Eq. (1), $v_{d c r e f}$ is the reference DC voltage, $v_{d c}$ is the actual DC voltage, $i_{\text {gref }}$ is the reference grid current, $i_{g}$ is the actual grid current, $k_{1}, k_{2}$ are the sliding coefficients.

Fig. 1(a) shows the Bidirectional converter and SMC Controller for G2V mode in Fig. 1(b). Table 1 shows the system parameters used for the simulation. A single phase $120 \mathrm{~V}, 60 \mathrm{~Hz}$ system is considered in this work. An effective design of the passive filters used in the circuit is very much necessary for the 
best operation of the EV. The design of passive components are obtained from (5) (6) (7) presented in the paper [3].

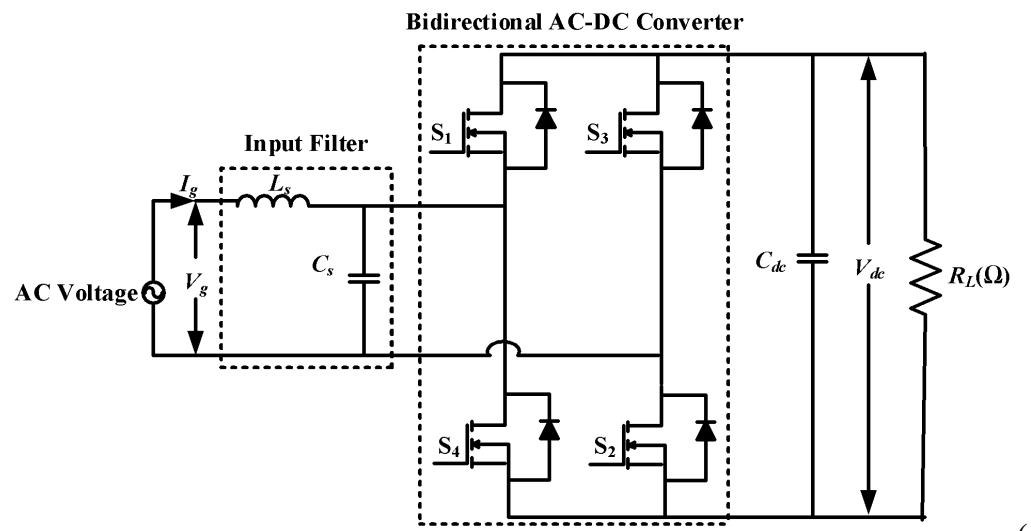

(a)

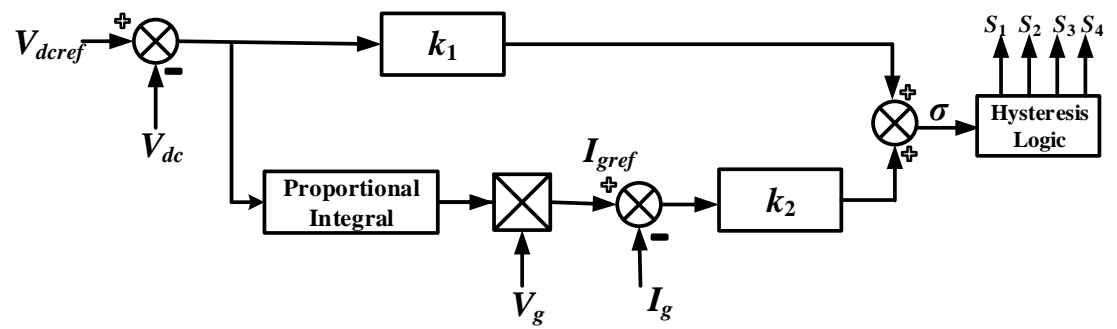

Figure 1. (a) Bidirectional converter (b) SMC Controller for G2V mode.

(b)

Fig. 2 shows the error voltage with hysteresis band. Fig. 3 shows the switching pulses applied to the bidirectional AC-DC converter. The grid voltage and current obtained are shown in Fig. 4 during G2V mode of operation. They are said to be in phase. Fig. 5 shows reference tracking of the DC voltage. The error and settling time is observed to be $2.5 \%$ and 0.16 s. Fig. 6 shows the input inductor current tracking waveform. The controller is observed to be smooth in tracking the grid current.

Table 1. System parameters

\begin{tabular}{ll}
\hline Parameters & Value \\
\hline Output power $P_{d c}$ & $5 \mathrm{~kW}$ \\
link voltage $V_{d c}$ & $400 \mathrm{~V}$ \\
Capacitor $C_{d c}$ & $2 \mathrm{mF}$ \\
AC Filter inductor $L_{s}$ & $0.75 \mathrm{mH}$ \\
Hysteresis band $h$ & $\pm 0.5 \mathrm{~V}$ \\
AC Filter capacitor $C_{s}$ & $50 \mu \mathrm{F}$ \\
System frequency $f_{s}$ & $60 \mathrm{~Hz}$ \\
Grid voltage $V_{g}$ & $120 \mathrm{~V} \mathrm{rms}$ \\
Control parameters $k_{1}, k_{2}$ & 10,20000
\end{tabular}

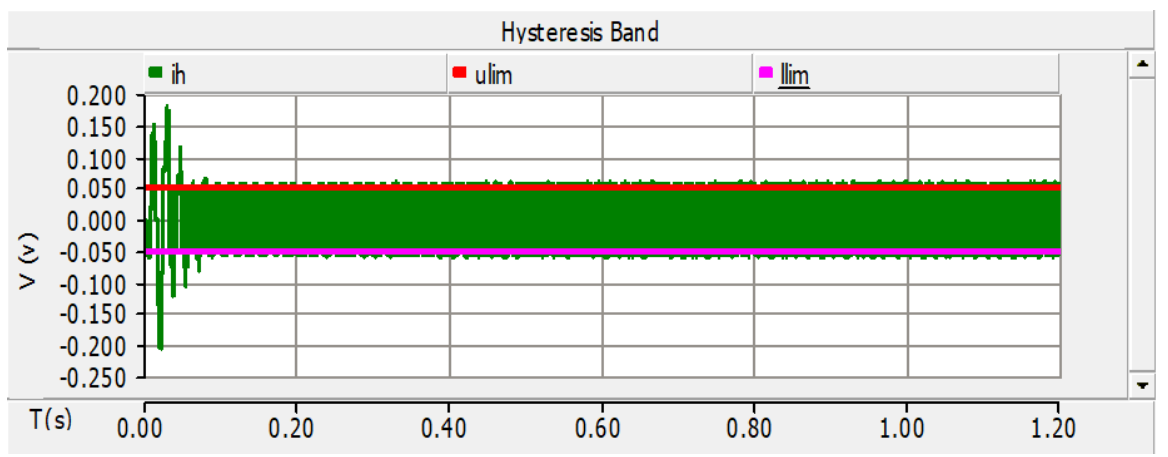

Figure 2. Error voltage with Hysteresis band. 


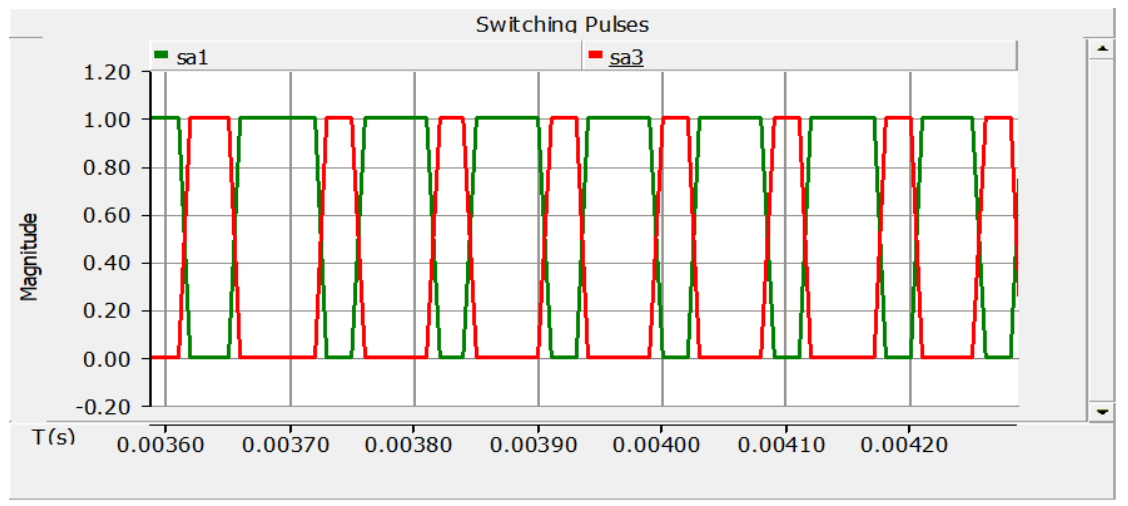

Figure 3. Switching Pulses to IGBT switches of AC-DC rectifier.

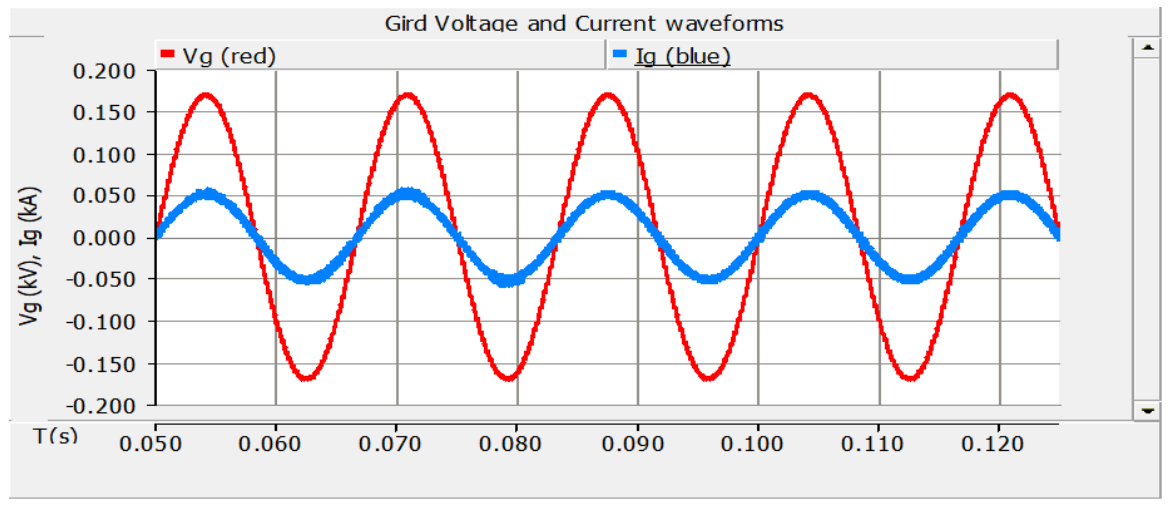

Figure 4. Voltage and Current of the grid.

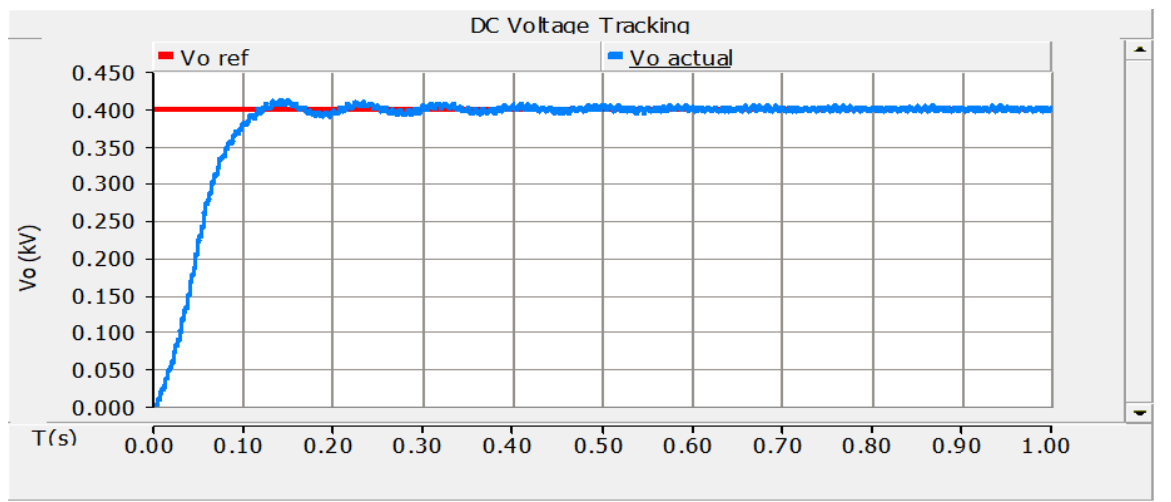

Figure 5. DC Voltage tracking in G2V mode.

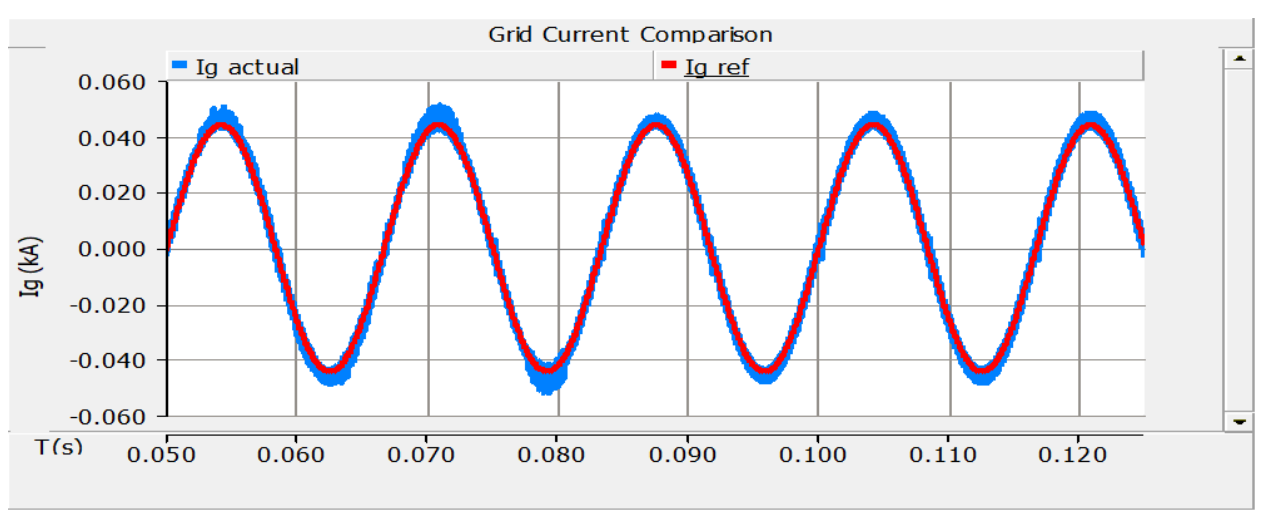

Figure 6. Grid current tracking in G2V mode. 


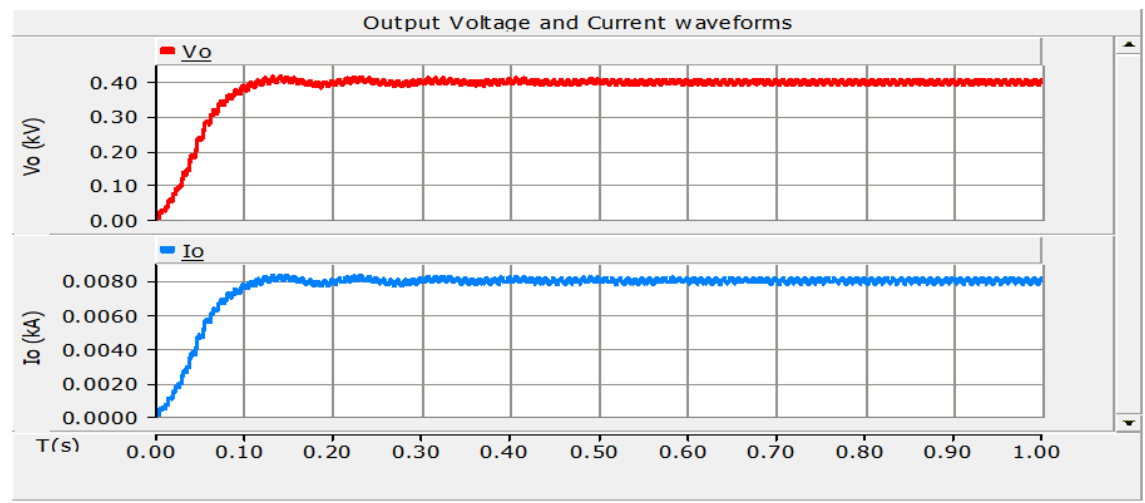

Figure 7. Output DC current and voltage in G2V mode.

Table 2. Harmonic components of grid voltage and current

\begin{tabular}{ccc}
\hline Harmonic order & Current THD & Voltage THD \\
\hline $3^{\text {rd }}$ & $0.415 \%$ & $1.505 \%$ \\
$5^{\text {th }}$ & $0.296 \%$ & $1.740 \%$ \\
$7^{\text {th }}$ & $0.219 \%$ & $1.70 \%$ \\
$9^{\text {th }}$ & $0.171 \%$ & $1.20 \%$ \\
$11^{\text {th }}$ & $0.139 \%$ & $0.38 \%$ \\
$13^{\text {th }}$ & $0.115 \%$ & $0.27 \%$ \\
\hline
\end{tabular}

\section{Grid current THD}

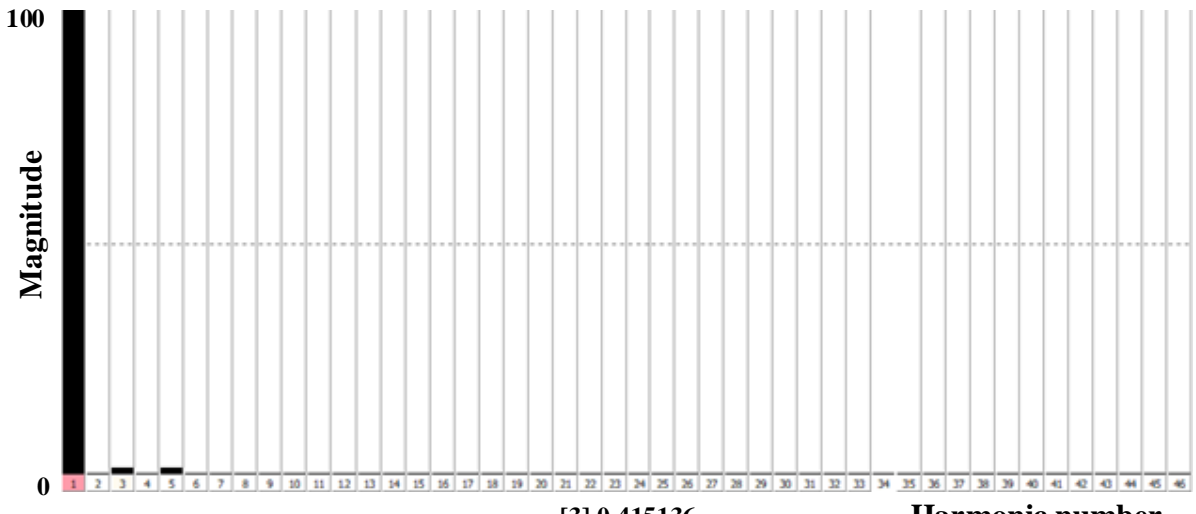

[3] 0.415136

Harmonic number

Grid Voltage THD

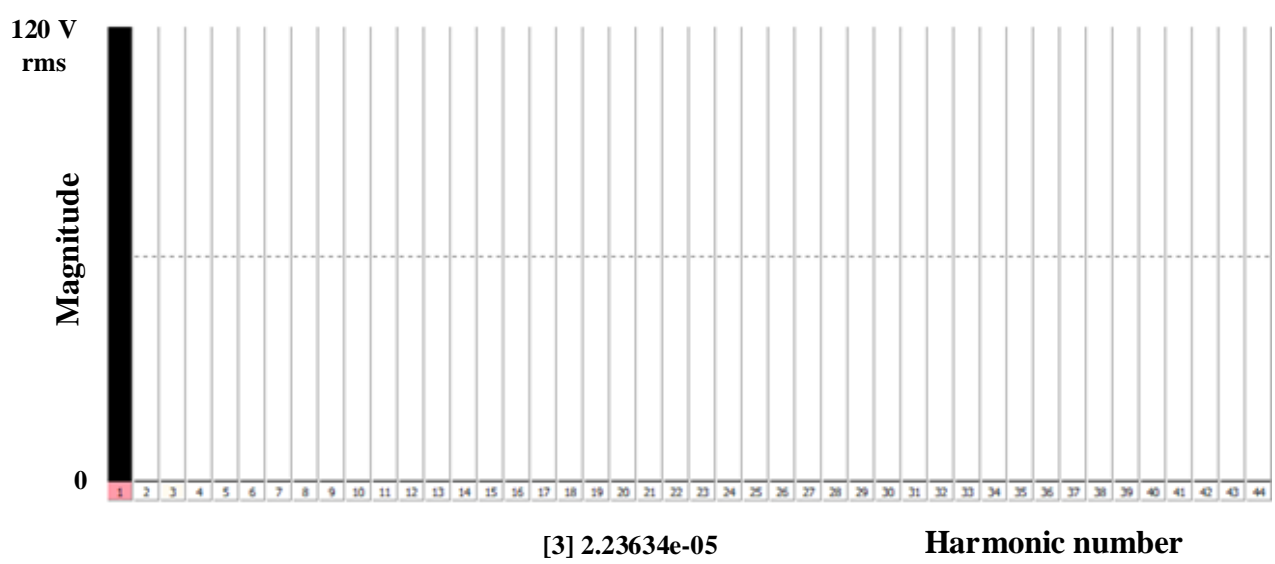

[3] 2.23634e-05

Harmonic number

(b)

Figure 8. (a) Grid current harmonic spectrum during G2V, (b) Grid voltage harmonic spectrum in G2V mode. 


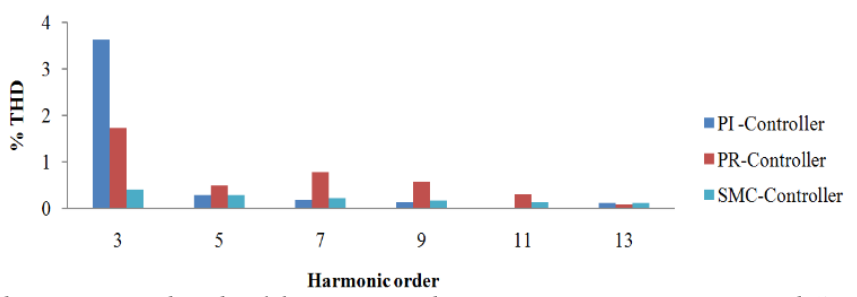

Figure 9. Grid current individual harmonic distortion using PI, PR and SMC controllers.

The output waveforms of DC voltage $400 \mathrm{~V}$ and current $8 \mathrm{~A}$ are shown in Fig. 7. It is observed that the SMC controller has better tracking capability. Error during steady state in the output voltage is $1 \%$ and input current is $2.4 \%$. Table 2 gives the grid voltage and current THDs. It observed that out of all odd order harmonic components the $3^{\text {rd }}$ order harmonic component is dominated. SMC controller clearly demonstrates the improvement in overcoming harmonic pollution. It is found that THD is $0.645 \%$ in grid current and 3.53\% in grid voltage. According to the IEEE 519-1992 standards, lower THD values less than 5\% is acceptable for the grid voltage and $15 \%$ for grid currents. Thus, the proposed controller is able to deliver the results within acceptable limits. Fig. 8(a) and Fig. 8(b) shows harmonic spectrums of grid voltage and current. It is observed that the $3^{\text {rd }}, 5^{\text {th }}$ and $7^{\text {th }}$ order harmonic components magnitude is low using SMC compared to PI and PR controllers in G2V mode of operation. It is presented in Fig. 9 .

\subsection{Grid frequency variation}

The controller is tested for grid frequency variation. During G2V operation, grid frequency is varied \pm $3 \%$ as per the standards available $(2.5 \%)$ of the fundamental frequency $(60 \mathrm{~Hz})$. During frequency variation, SMC tracks the reference dc voltage without any distortions. Fig. 10 (a) shows the dc voltage tracking for grid frequency variation. The frequency from $0-0.4 \mathrm{~s}$ is $60 \mathrm{~Hz}$ and from $0.4 \mathrm{~s}$ to $1 \mathrm{~s}$ the grid frequency is $58.2 \mathrm{~Hz}$. The corresponding dc voltage tracking is shown in Fig. 10 (b). The controller is able to track the reference DC voltage even during grid frequency variations. The steady state error is found to be $2.5 \%$. Similar results are presented in Fig. 11 (a) and Fig. 11 (b) when the variation is from $60 \mathrm{~Hz}$ to $61.8 \mathrm{~Hz}$. The controller is said to be working well with very less steady state error.

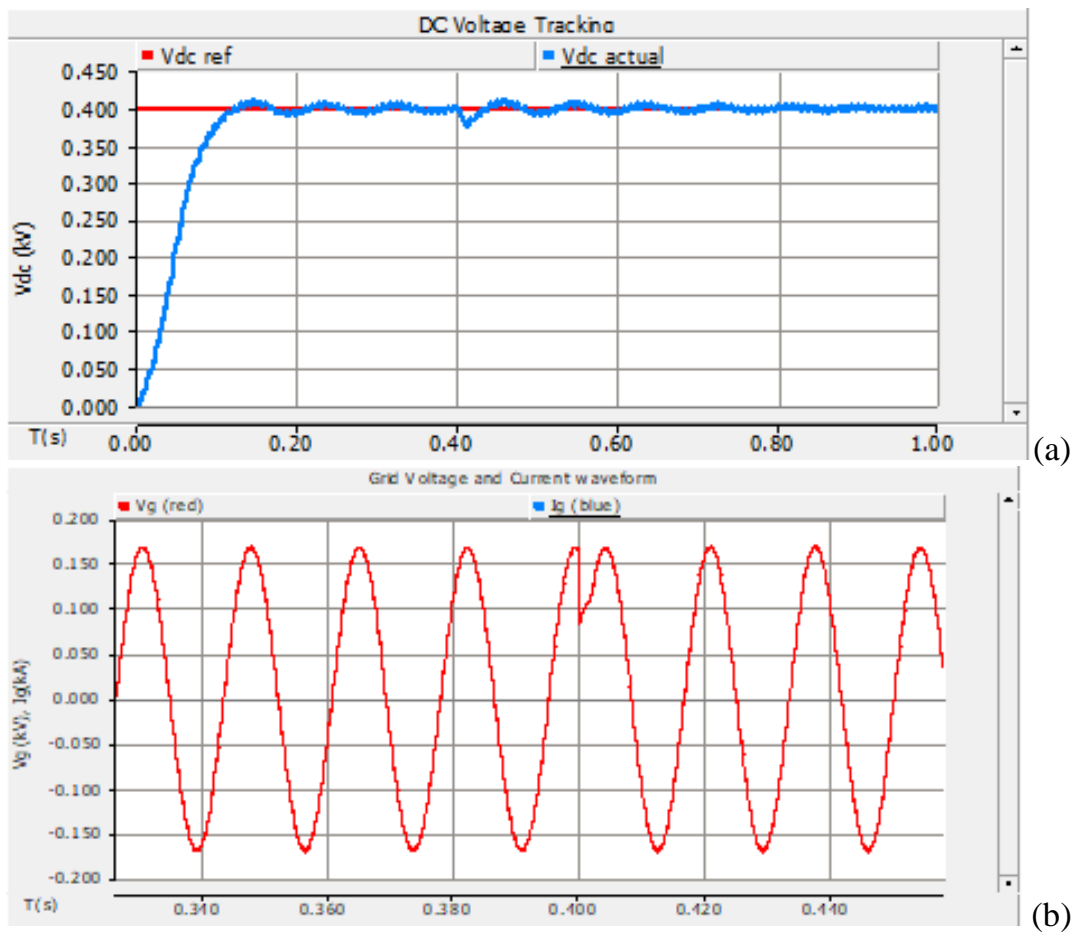

Figure 10. (a) DC voltage tracking (b) Grid voltage waveform at frequency of $58.2 \mathrm{~Hz}$. 


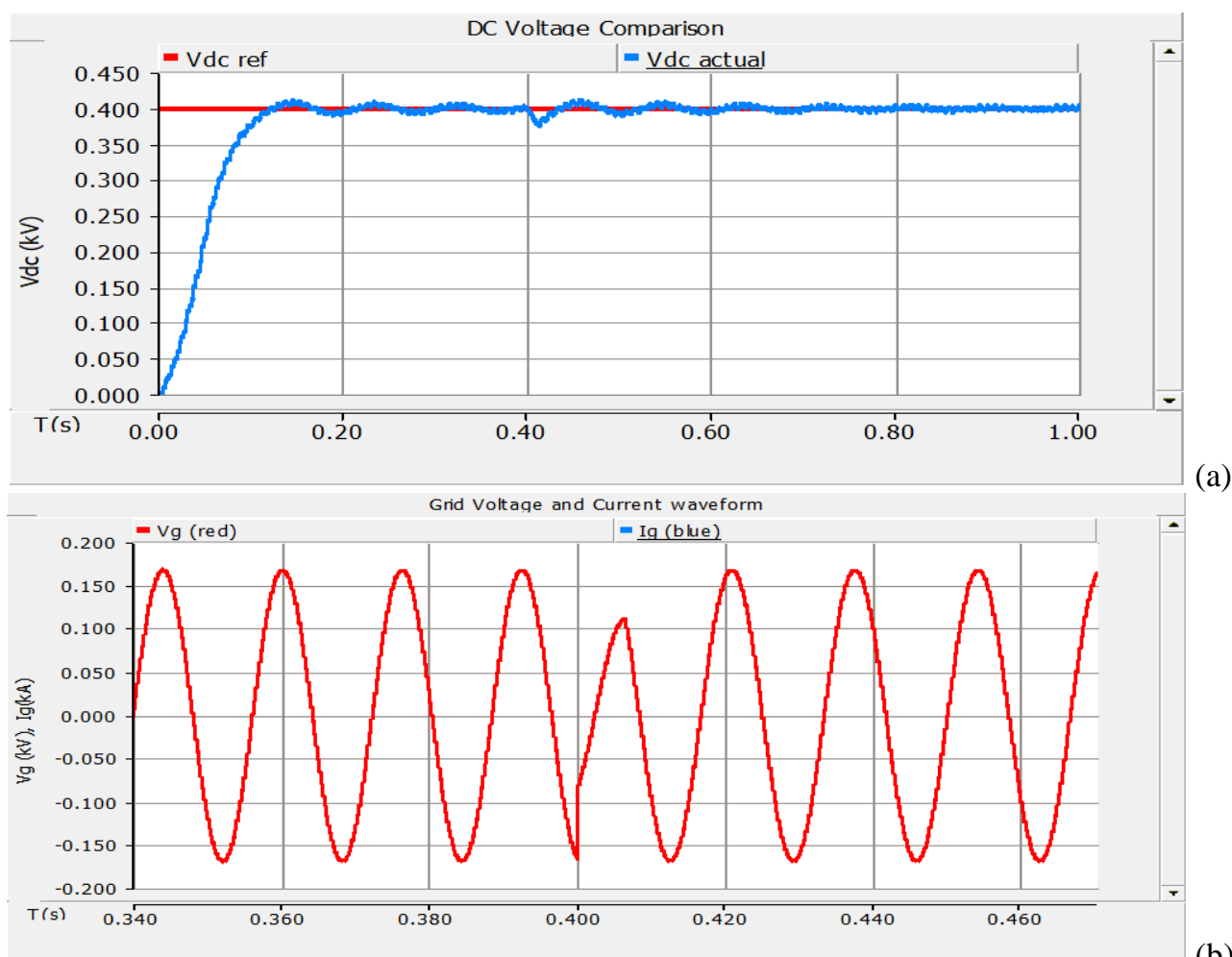

(a)

Figure 11. (a) DC voltage tracking (b) Grid voltage waveform at frequency of $61.8 \mathrm{~Hz}$.

It is clear that SMC follows the reference voltage with less distortion for grid frequency variation. Hence SMC can be effectively used for electric vehicle charging systems.

\subsection{State Space Model for SMC Controller in G2V mode}

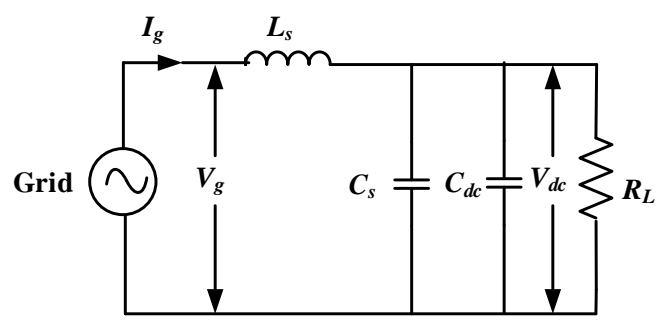

Figure 12. Equivalent circuit in G2V operation.

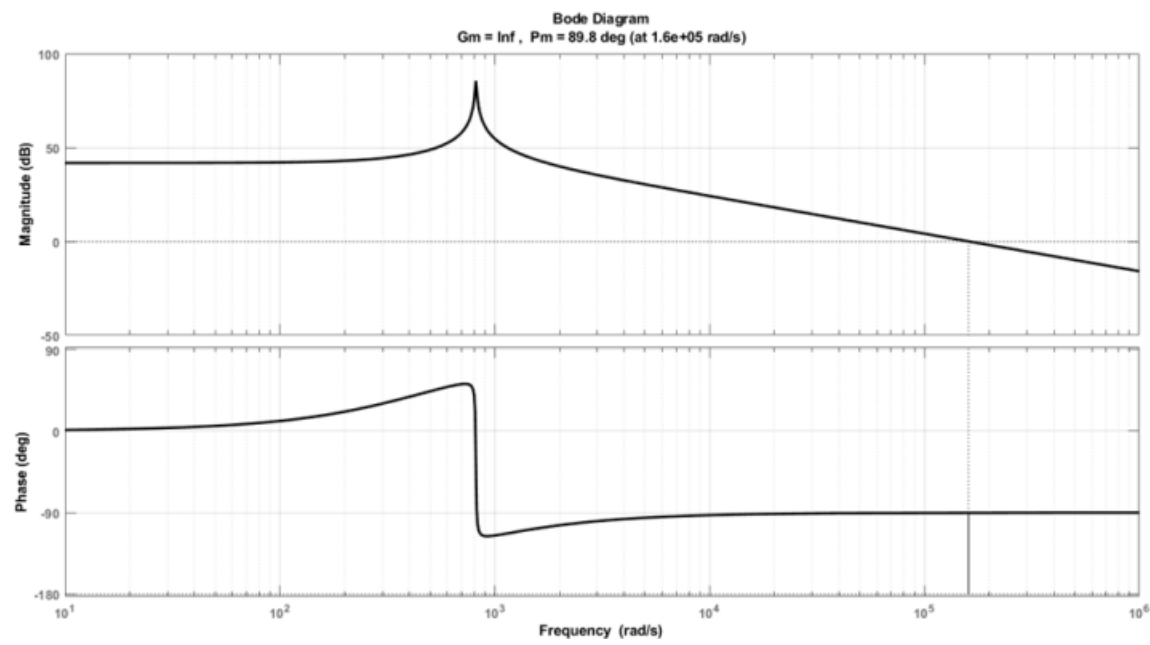

Figure 13. Frequency response characteristic. 
The electric vehicle equivalent circuit is shown in Fig.12. The state space model of the system is obtained by taking the dc voltage and grid current as state variables. Using state feedback approach, to test the stable operation of the system, frequency response plot is obtained with the selected state variables. The model is given by Eq. 2 .

$$
A=\left[\begin{array}{cc}
0 & \frac{-1}{L_{s}} \\
\frac{1}{C_{d c}} & \frac{-1}{R_{L} C_{d c}}
\end{array}\right] ; B=\left[\begin{array}{c}
\frac{V_{g}}{L_{s}} \\
0
\end{array}\right] ; C=\left[\begin{array}{ll}
1 & 1
\end{array}\right]
$$

Where $L_{s}$ is the input inductance, $C_{d c}$ is the dc output capacitor, $R_{L}$ is the load resistance and $V_{g}$ is the grid voltage. The response of the systems is shown in Fig. 13. Both the gain margin and phase margin are positive and the system is said to be stable. The simulation results presented from Fig. 2 to Fig. 11 are said to be verified through this state space model. The output equation is given by Eq. (3)

$$
Y=C x
$$

\section{SMC CONTROLLER FOR V2G OPERATION}

In V2G operation, bidirectional AC/DC converter acts as inverter and the energy stored in the battery is given back to the grid. Bidirectional converter with SMC controller in V2G mode of operation is shown in Fig. 14 [7-8]. The error generated is compared with a repetitive waveform of switching frequency 10 $\mathrm{kHz}$.

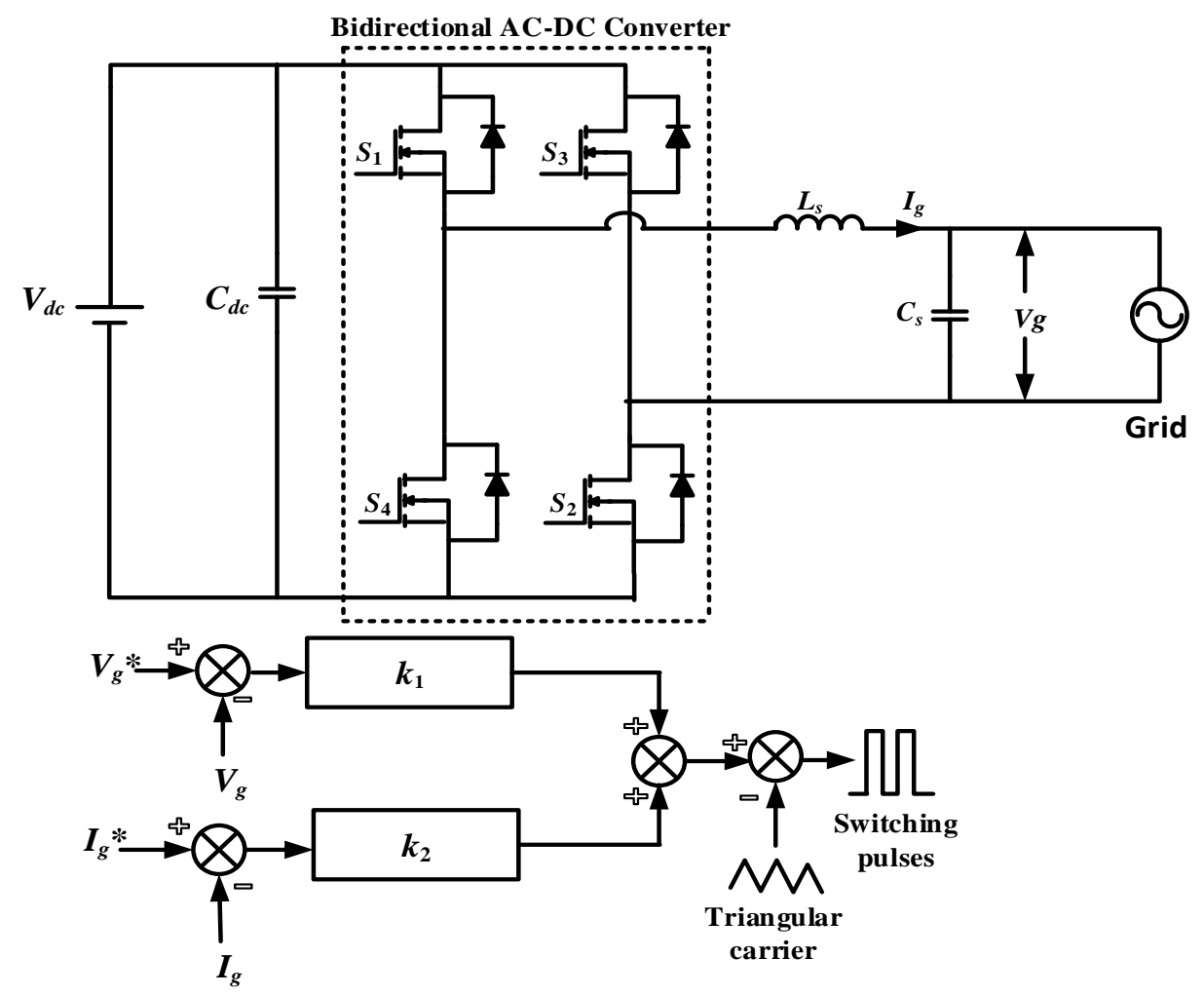

Figure 14. Bidirectional converter with SMC controller in V2G mode. 


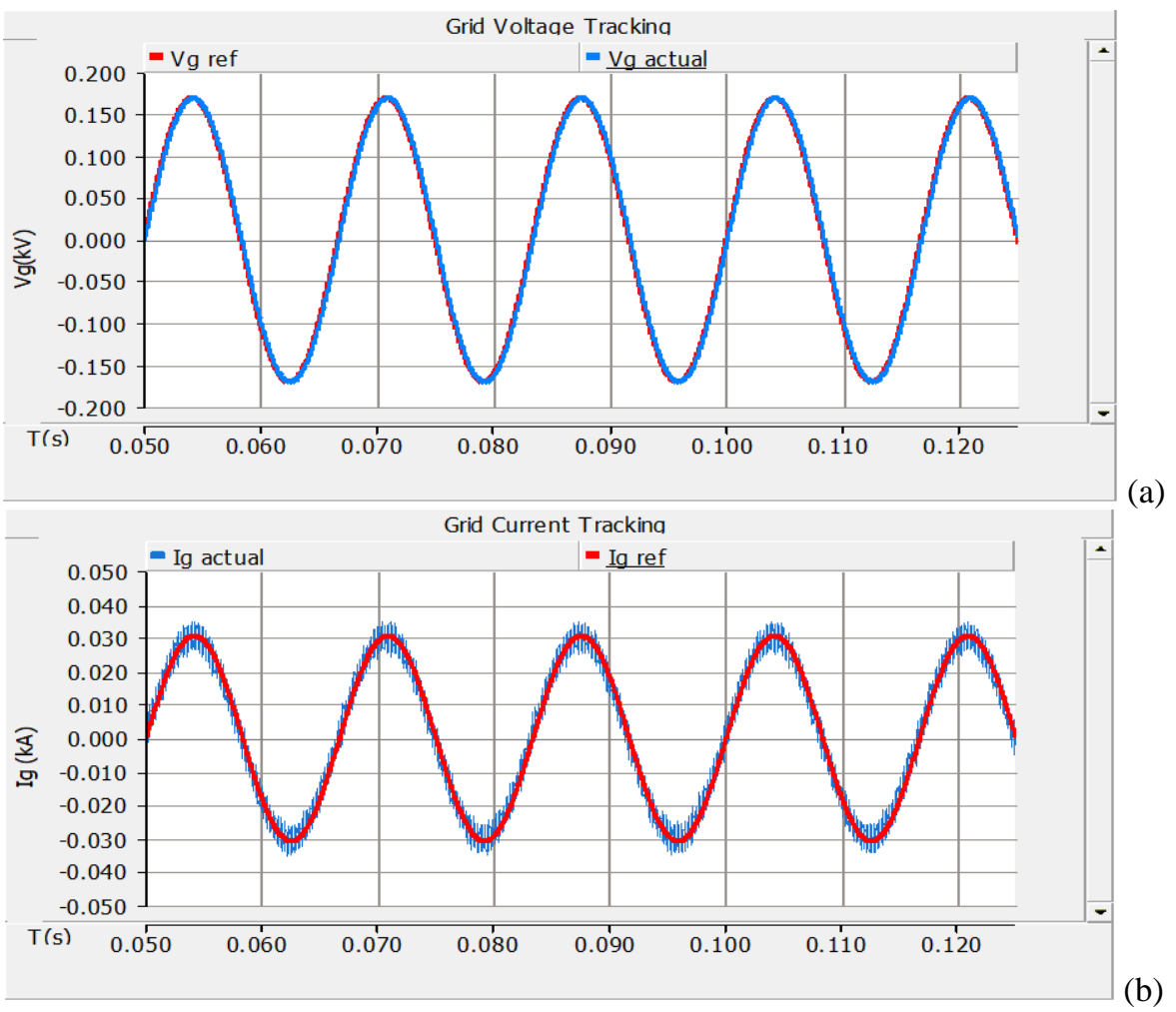

Figure 15. (a) Grid voltage tracking (b) Grid current comparison of SMC in V2G mode.
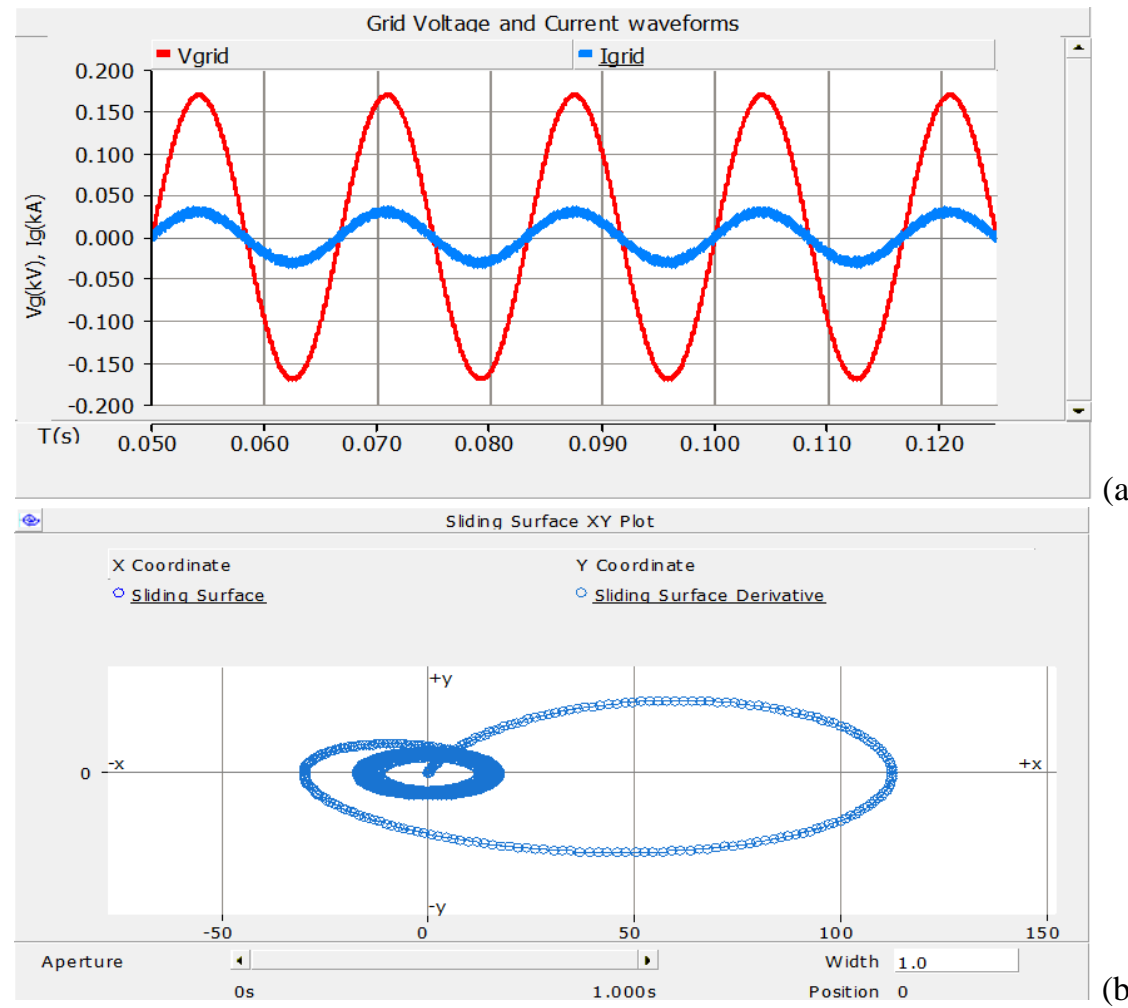

(a)

Figure 16. (a) Output Grid voltage and current (b) Phase Plane plot showing the convergence.

For a unity power factor load of $P_{L}=5 \mathrm{~kW}$, using the following expressions Eq. (4)-(7), the grid current reference $i_{\text {gref }}$ and reference voltage across the capacitor $v_{\text {cref }}$ are derived for obtaining the sliding surface $\sigma$. For a lossless system and unity power load $\cos \phi$ is one. Fig. 16(a) results are obtained accordingly. 


$$
\begin{gathered}
P_{g}=v_{g} i_{g} \cos \phi \\
v_{g}=120 \sqrt{2} \sin \omega t \\
i_{\text {gref }}=\frac{P_{g}}{v_{g} \cos \phi}=29.58 \sin \omega t \\
v_{\text {cref }}=v_{g}+L_{s} \frac{d_{g}}{d t}=7.33 \cos \omega t+169.7 \sin \omega t
\end{gathered}
$$

Table 3. Harmonic Components of Grid Voltage and Current using SMC Controller

\begin{tabular}{ccc}
\hline Harmonic order & Current THD & Voltage THD \\
\hline $3^{\text {rd }}$ & $0.295 \%$ & $2.144 \%$ \\
$5^{\text {th }}$ & $0.381 \%$ & $0.757 \%$ \\
$7^{\text {th }}$ & $0.125 \%$ & $2.238 \%$ \\
$9^{\text {th }}$ & $0.099 \%$ & $1.465 \%$ \\
$11^{\text {th }}$ & $0.179 \%$ & $1.261 \%$ \\
$13^{\text {th }}$ & $0.122 \%$ & $0.949 \%$ \\
\hline
\end{tabular}

Fig. 15 (a) shows the grid voltage which follows the reference grid voltage. Fig. 15(b) shows the Grid current tracking. The steady state error in the grid current is found to be $9.3 \%$. Good tuning of the sliding coefficients leads to less steady state error. The grid voltage and current are said to be in phase as shown in Fig. 16 (a). Fig. 16(b) shows the phase plot of the grid voltage in V2G operation. It is drawn between the sliding surface $(\sigma)$ and the derivative of the sliding surface $(\dot{\sigma})$. The plane is said to be reaching the origin within a short time. It depicts the system convergence to stability. Table 3 shows grid voltage and current individual harmonic contents. Fig. 17 (a) shows the THD spectrums for the grid current and Fig. 17 (b) the grid voltage THD. The grid current THD present is found to be $1.95 \%$.
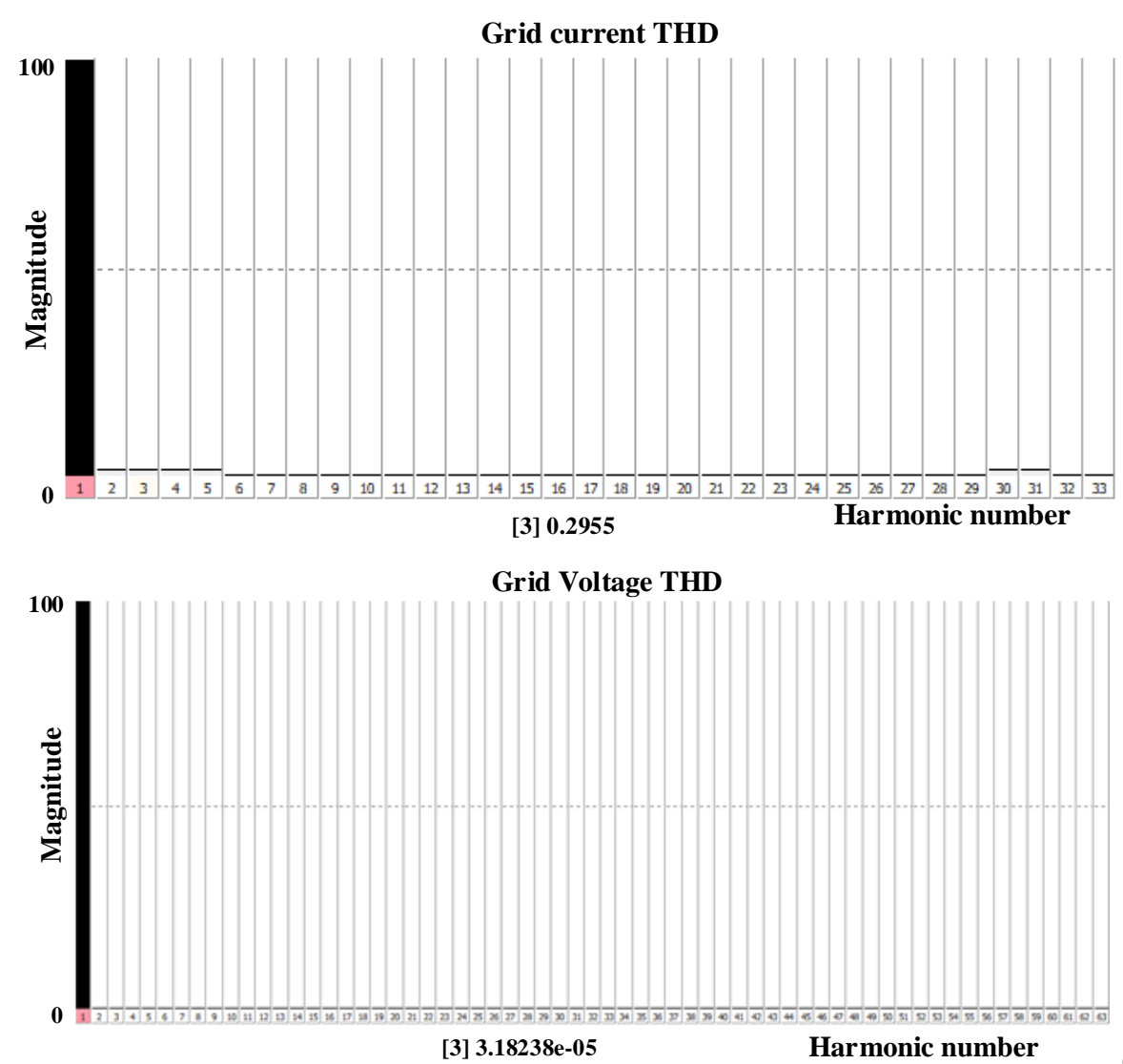

(a)

(b)

Figure 17. (a) Grid current harmonic spectrum (b) Grid voltage harmonic spectrum in V2G mode. 


\subsection{Variation in Grid Frequency}

In V2G mode also, SMC response towards grid frequency variation is observed. Fig. 18(a) shows the grid voltage waveform. From 0 to $0.4 \mathrm{~s}$ the grid voltage frequency is $60 \mathrm{~Hz}$ and from 0.4 to $1 \mathrm{~s}$ the grid voltage frequency is $58.2 \mathrm{~Hz}$ and the corresponding grid current tracking waveform is shown in Fig. 18(b) the steady state error is 9.3\%. Fig. 19(a) and Fig. 19(b) shows the grid voltage waveform and corresponding grid current tracking waveform at $61.8 \mathrm{~Hz}$. The response of SMC is found to be satisfactory.
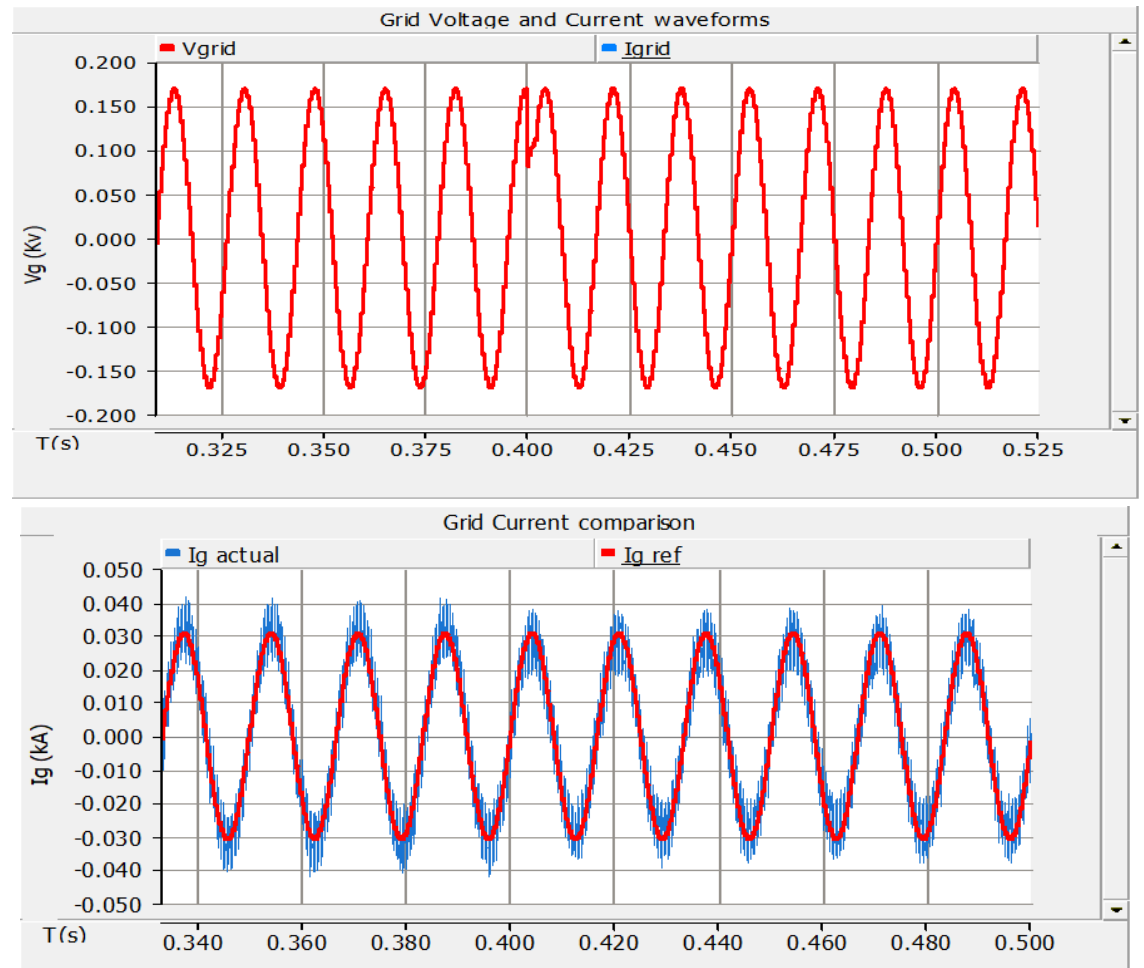

Figure 18. (a) Grid voltage waveform (b) Grid Current tracking waveform at $58.2 \mathrm{~Hz}$.

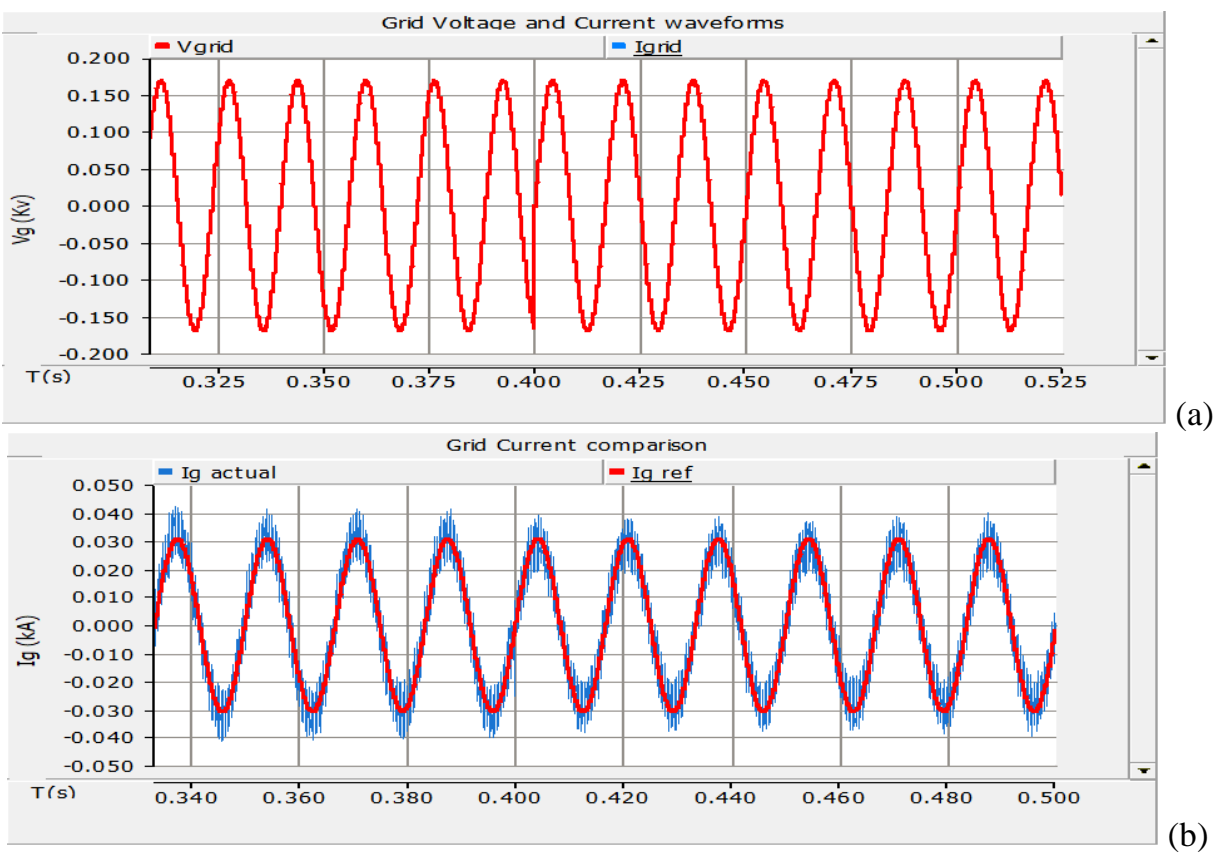

Figure 19. (a) Grid voltage waveform (b) Grid Current tracking waveform at $61.8 \mathrm{~Hz}$. 


\subsection{State Space Model for SMC Controller in V2G mode}

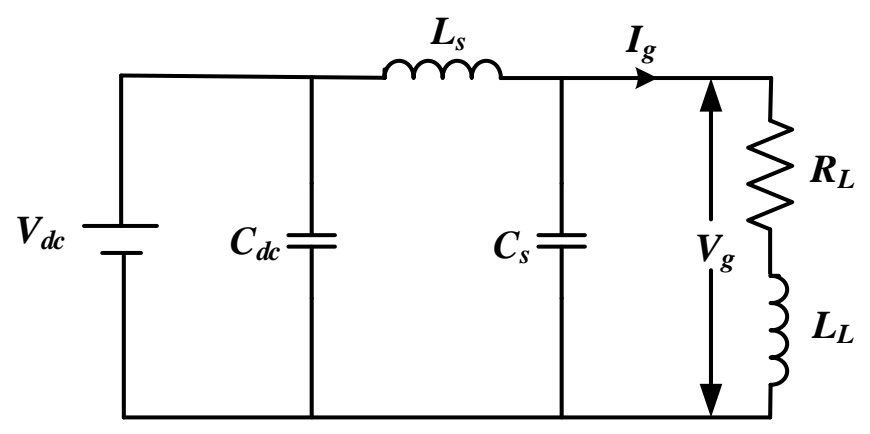

Figure 20. Equivalent circuit in V2G mode.

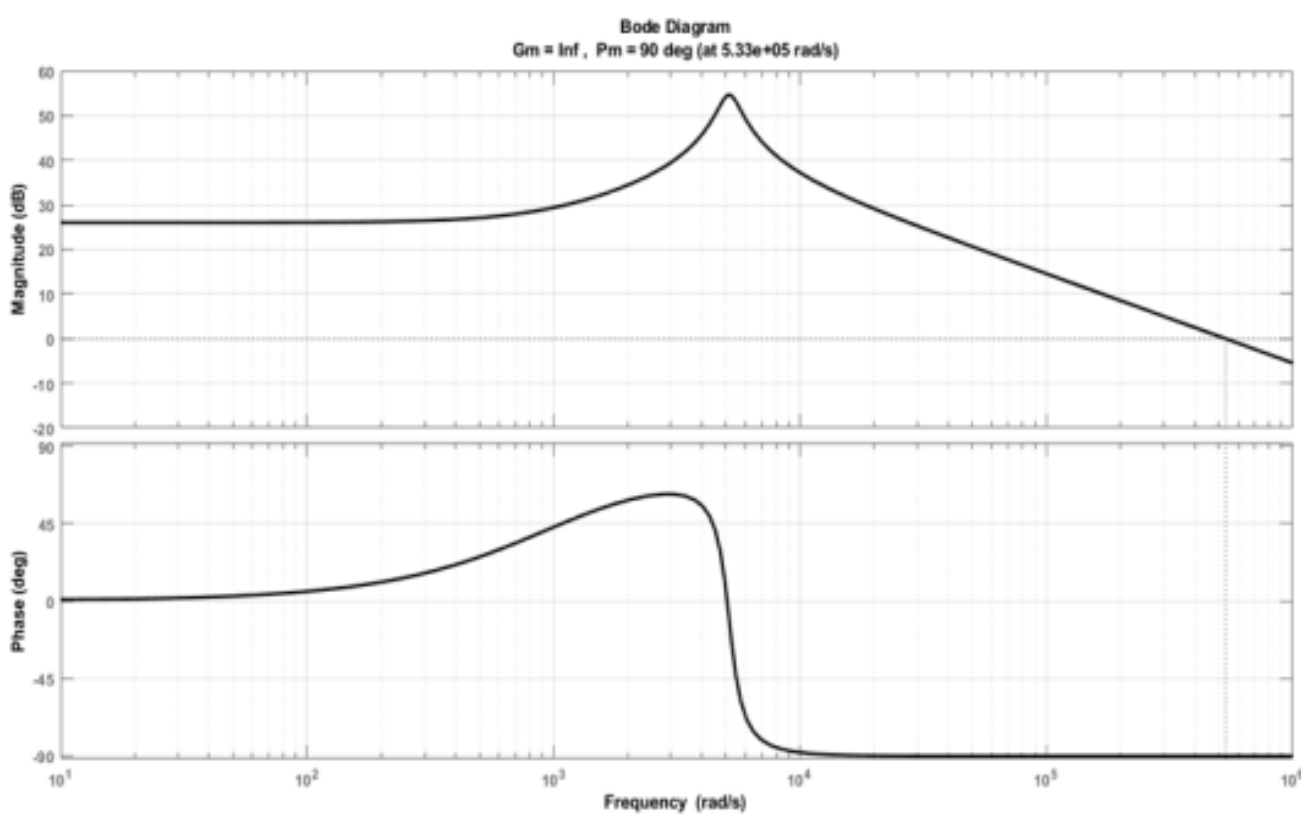

Figure 21. Bode plot during V2G mode.

The system state space model is obtained for the Fig. 20 as Eq. (8)

$$
A=\left[\begin{array}{cc}
\frac{-1}{C_{s} Z_{L}} & \frac{1}{C_{s}} \\
\frac{-1}{L_{S}} & 0
\end{array}\right] ; B=\left[\begin{array}{c}
0 \\
\frac{V_{d c}}{L_{s}}
\end{array}\right] ; C=\left[\begin{array}{ll}
1 & 1
\end{array}\right]
$$

Fig. 20 shows the equivalent circuit of the single-phase bidirectional DC-AC inverter in V2G operation. Where $L_{s}$ is the source side inductance, $C_{s}$ is the source side capacitance, $Z_{L}$ is the grid impedance given by $Z_{L}=R_{L}+j X_{L}$ and $V_{d c}$ is the battery voltage. The frequency response plot characteristics of the system is shown in Fig. 21. It is found that the system is stable [8].

\section{ELECTRIC VEHICLE CHARGING AND DISCHARGING WITH THE PROPOSED CONTROLLER}

Having done the G2V and V2G modes operating satisfactorily, the charging and discharging phenomenon are analyzed using the bidirectional converter for an EV with a single equivalent circuit. Fig. 22 (a) shows the Electric Vehicle Charging and Discharging configuration circuit. It comprises 
three main parts namely bidirectional AC/DC, DC/DC converter and a battery [9]. The electric vehicle circuit configuration consisting of two stages [10]. First stage acts as a converter/inverter and the second stage consists of a DC/DC converter which works as a buck converter in charging and boost converter during discharging modes of operation. The stored battery energy is in the form of chemical energy in charging mode and energy is supplied to load during discharging mode. In this section, charging and discharging operations are discussed using SMC. Fig. 22 (b) shows the simplified block diagram of the SMC controller.
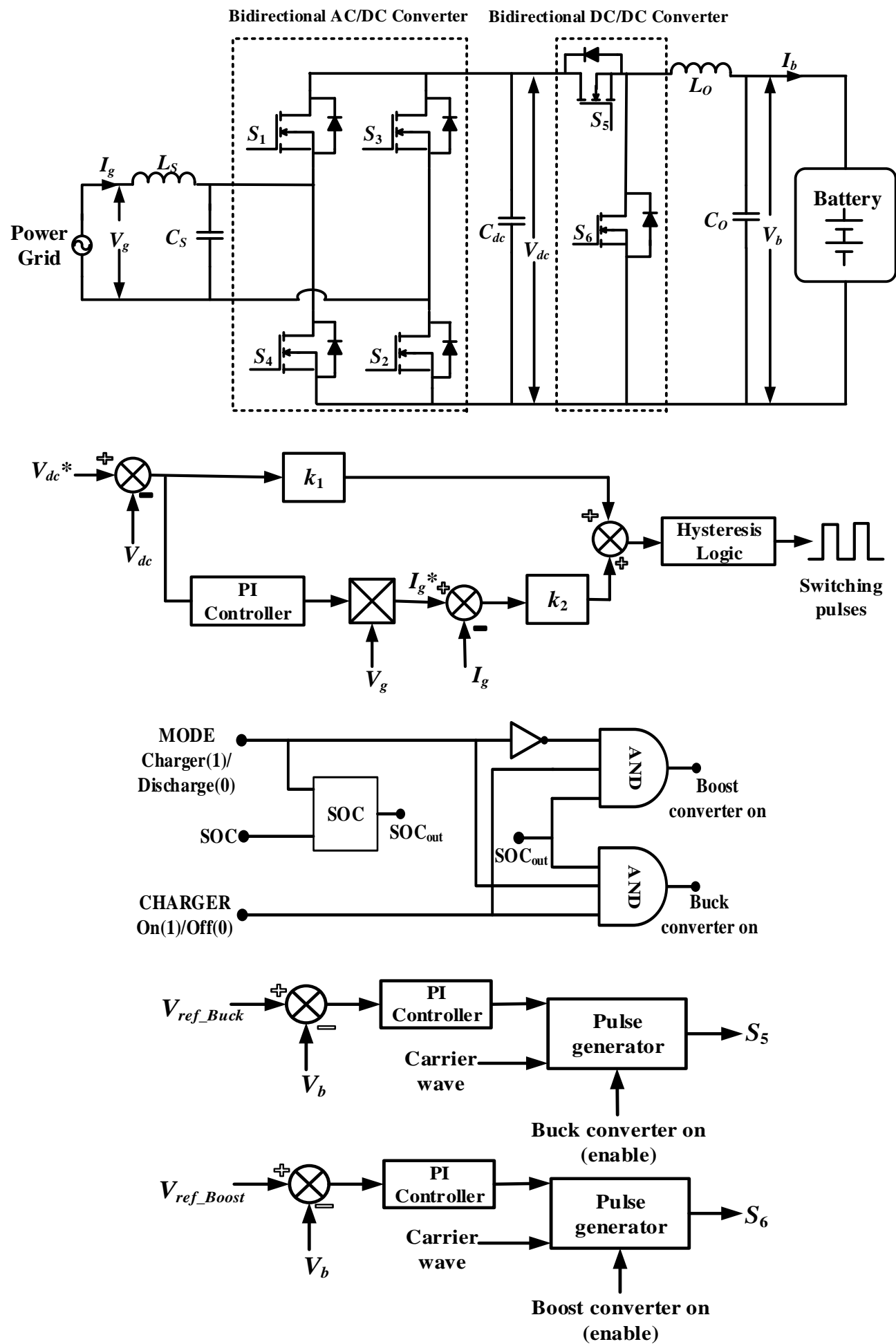

(b)

Figure 22(a). EV Charging and Discharging Configuration (b) Control block diagram of an SMC (c) Upper level control (d) Lower level control for DC-DC Converter. 
Fig. 22(c) shows the upper level and Fig. 22(d) shows the lower level controllers for the bidirectional DC-DC converter. In upper level control depending on the battery SOC between 5\% to 100\% and mode of operation i.e. charging or discharging mode, $\mathrm{SOC}_{\text {out }}$ is derived. Then $\mathrm{SOC}_{\text {out }}$, mode of operation and Charger ON/OFF are given to the logic circuits to produce a signal to enable the buck or boost converter. Accordingly switching pulses are generated using Fig. 22(d) to the switches of the Buck/Boost converter. Similarly, for lower level control the switching pulses are generated based on the voltage error and buck or boost converters are turned on with a logic signal. Table 4 shows the simulation parameters used.

Table 4 Circuit Configuration parameters

\begin{tabular}{ll}
\hline Parameters & Value \\
\hline Grid voltage $V_{g}$ & $120 \mathrm{~V} \mathrm{rms}$ \\
System frequency $f_{s}$ & $60 \mathrm{~Hz}$ \\
AC Filter inductor $L_{s}$ & $0.75 \mathrm{mH}$ \\
AC Filter capacitor $C_{s}$ & $20 \mu \mathrm{F}$ \\
DC Capacitor $C_{d c}$ & $2 \mathrm{mF}$ \\
Inductor $L_{o}$ & $41 \mu \mathrm{H}$ \\
Capacitor $C_{o}$ & $600 \mu \mathrm{F}$ \\
Battery capacity & $100 \mathrm{Ah}$ \\
Hysteresis band $h$ & $\pm 0.5 \mathrm{~V}$ \\
SMC Controller parameters $k_{1}, k_{2}$ & 10,20000 \\
\hline
\end{tabular}

\subsection{Charging Mode of Operation (G2V)}

Electric vehicle is charged from the grid in this mode of operation. Fig. 23(a) represents the instantaneous switching frequency waveform with $11 \mathrm{kHz}$ as maximum switching frequency. The grid current and voltage waveforms in charging with the SMC controller are shown in Fig. 23(b). It depicts the in-phase relation. Fig. 23(c) shows the DC voltage reference tracking, $1 \%$ steady state error and $0.1 \mathrm{~s}$ settling time.

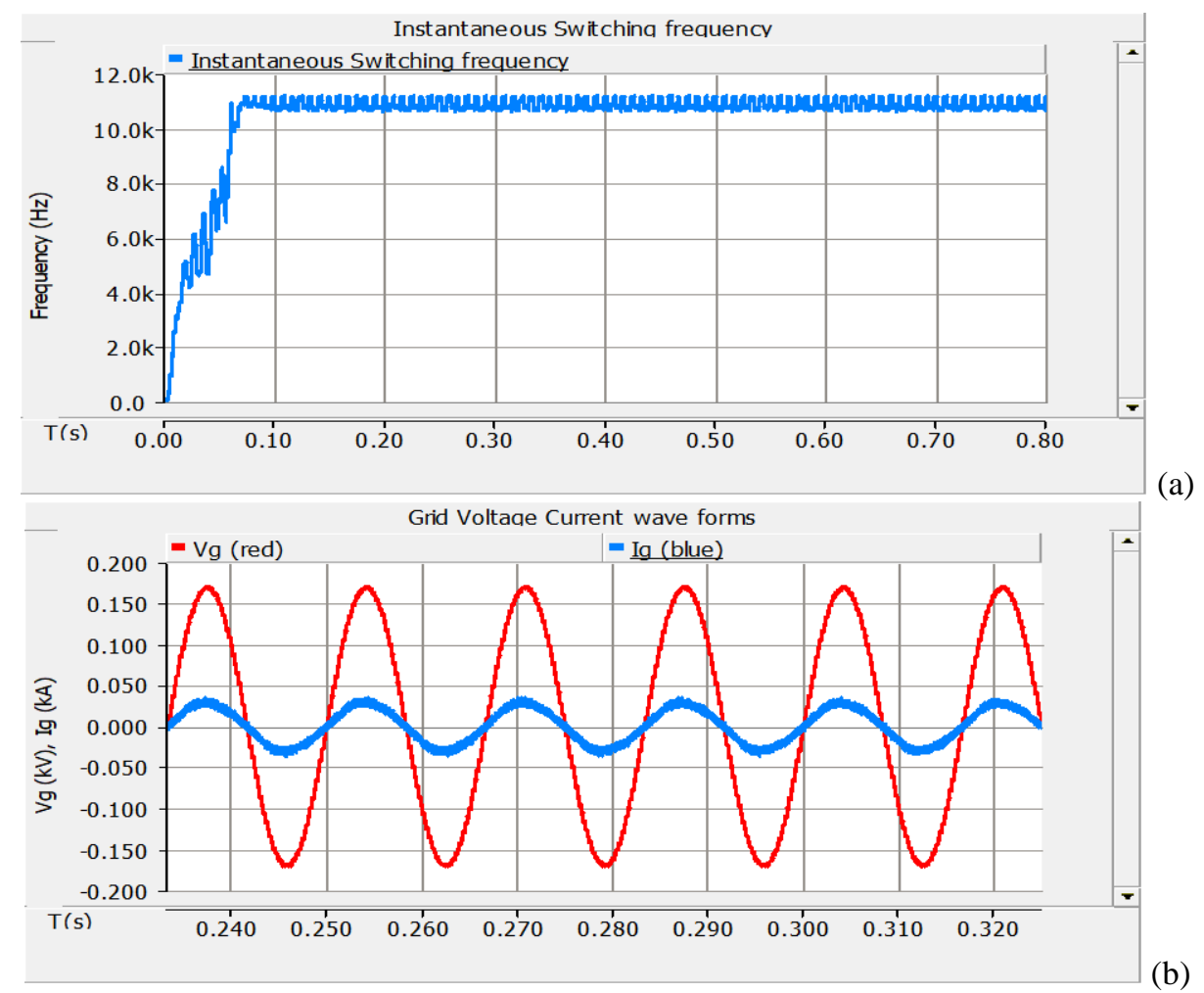




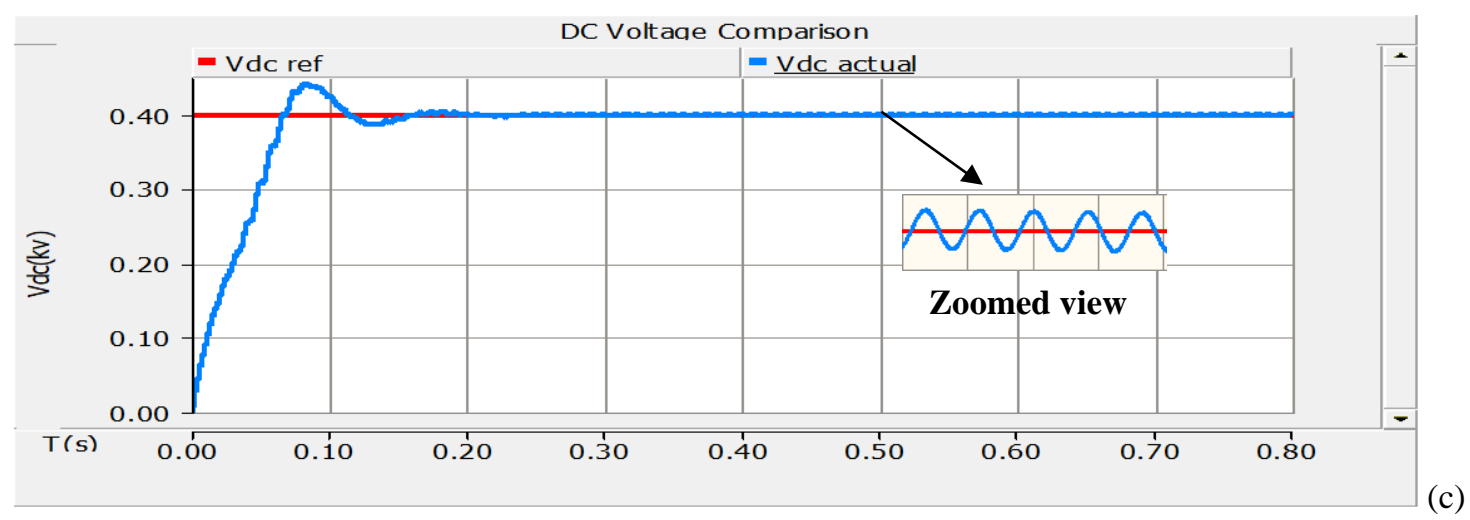

Figure 23(a) Switching frequency waveform (b) Grid Voltage and Current waveforms (c) DC Voltage tracking.

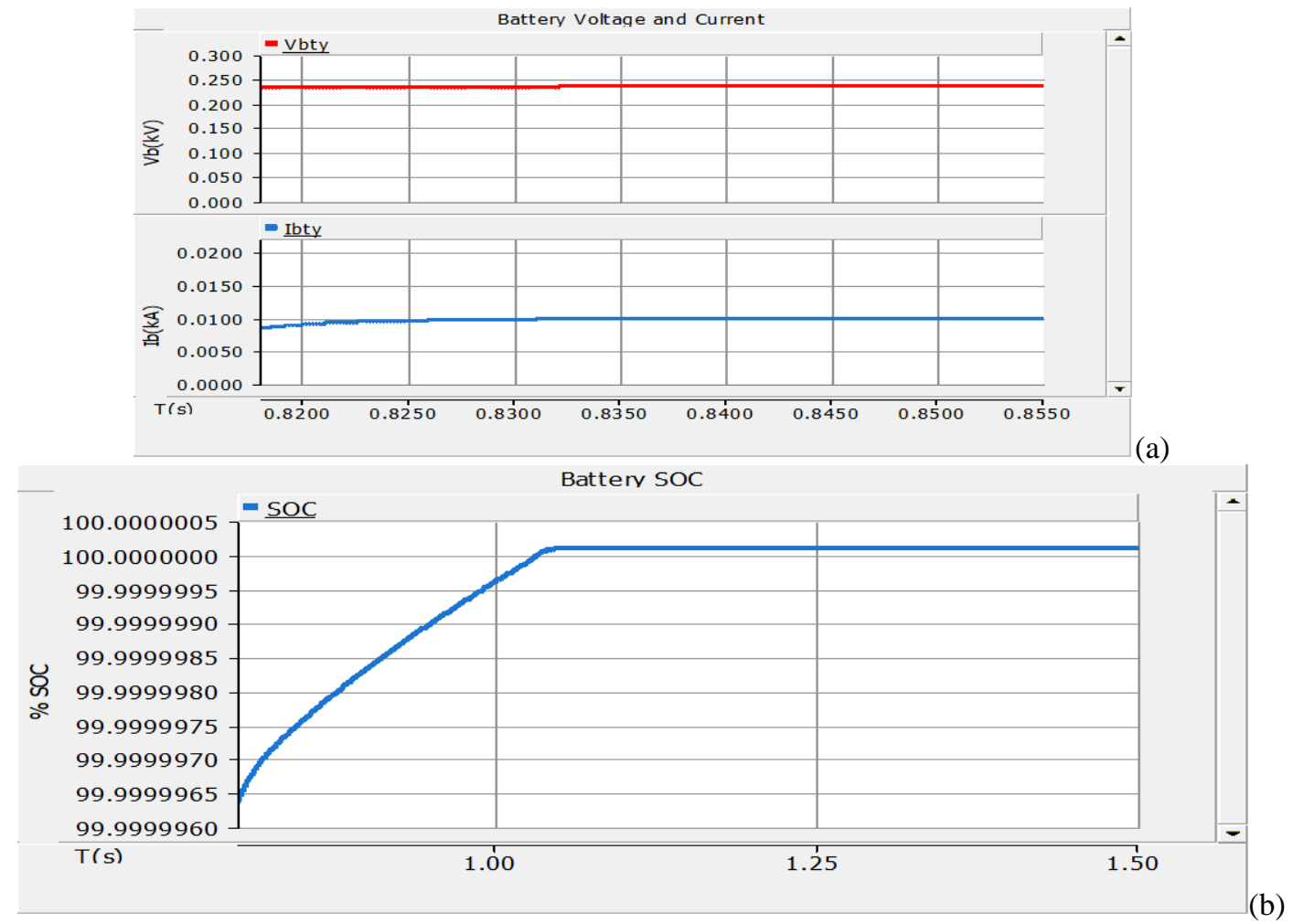

Figure 24(a) Battery Voltage and Current (b) Battery SOC.

Fig. 24(a) shows voltage across the battery and battery current during charging mode and corresponding SOC of battery is shown in Fig. 24 (b). Table 5 shows the odd numbered harmonic components of grid current during electric vehicle charging. The grid current THD and grid voltage THD is $3.28 \%$ and $0.038 \%$ respectively and are within the IEEE-519 standards. Fig. 25 shows the grid current THD spectrum.

Table 5 Odd harmonic Components- Grid current

\begin{tabular}{ll}
\hline Harmonic order & Grid Current Individual THD\% \\
\hline 3 & 0.850 \\
5 & 2.190 \\
7 & 1.399 \\
9 & 1.035 \\
11 & 0.950 \\
13 & 0.948 \\
\hline
\end{tabular}




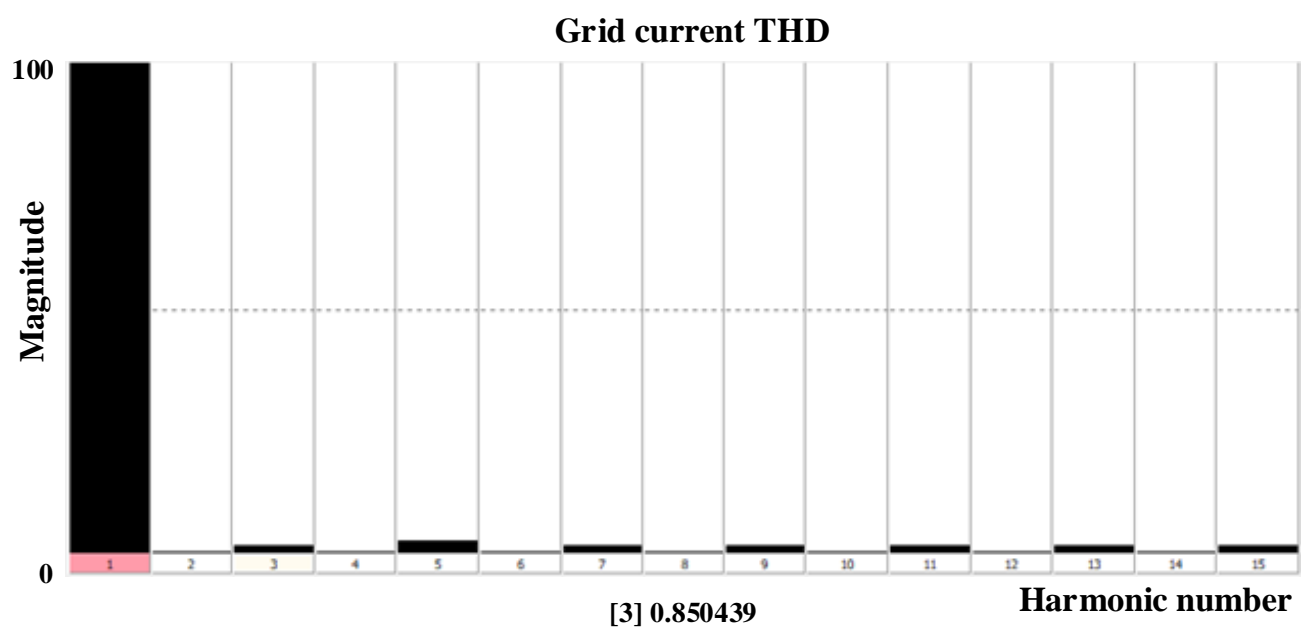

Figure 25. Grid current harmonic spectrum during Charging Mode of operation.

\subsubsection{State Space Model for SMC Controller during charging}

The equivalent circuit for the electric vehicle charging mode of operation is given in Fig. 26 (a) and the transfer function for the equivalent circuit is obtained as (8).

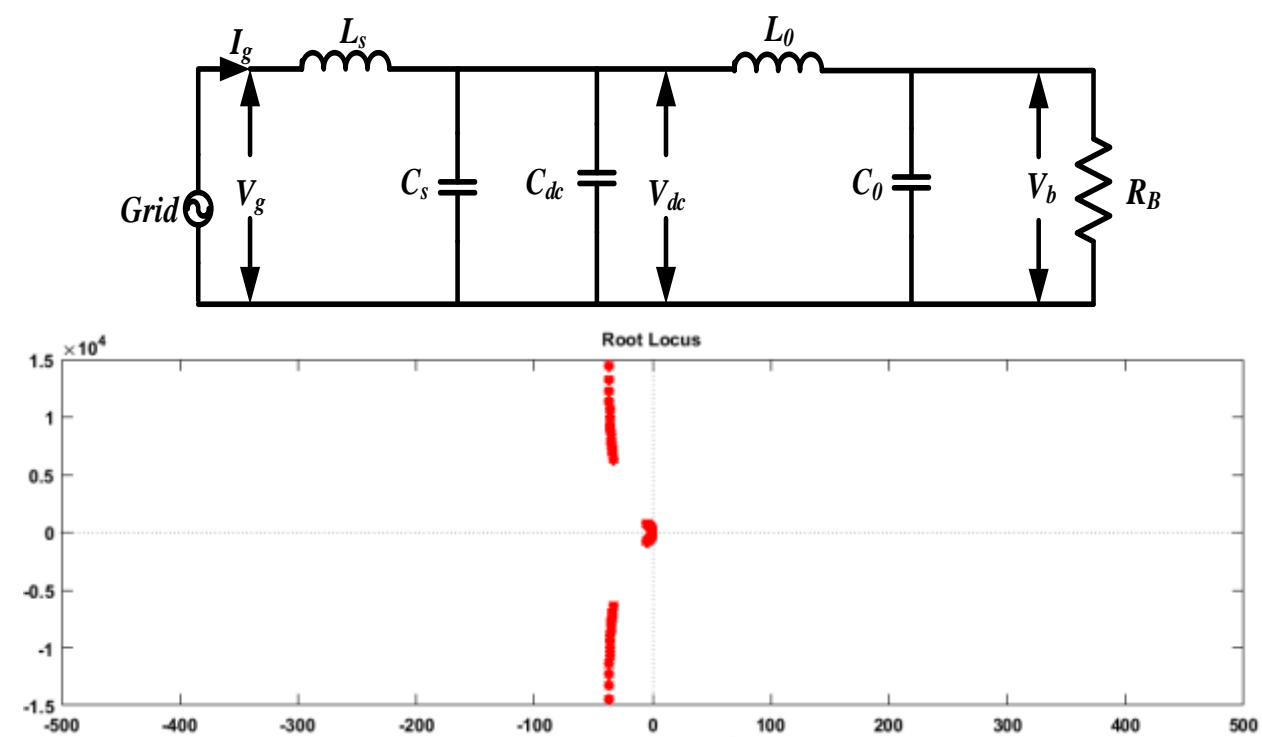

Figure 26. (a) Electric vehicle charging equivalent circuit. (b) Root locus showing the system stability.

The transfer function for the electric vehicle charging circuit is given by;

$$
G_{(s)}=\frac{1.561 \times 10^{12} s^{2}+1.197 \times 10^{14} s+1.041 \times 10^{15}}{s^{4}+76.67 s^{3}+4.132 \times 10^{7} s^{2}+4.509 \times 10^{8} s+2.71 \times 10^{13}}
$$

Fig. 26(b) shows the root locus of the transfer function obtained. The root locus depicts the stability of the system with unmodeled dynamics. The roots are on the left half of the s-plane.

\subsection{Discharging Mode of operation (V2G)}

Fig. 27(a) shows the grid voltage and current waveforms during discharging operation. Power flows from battery to the grid during discharge operation. It is shown that the grid current is in phase opposition with grid voltage. Fig. 27(b) shows the tracking of grid current and the steady state error is found to be $1.52 \%$. 


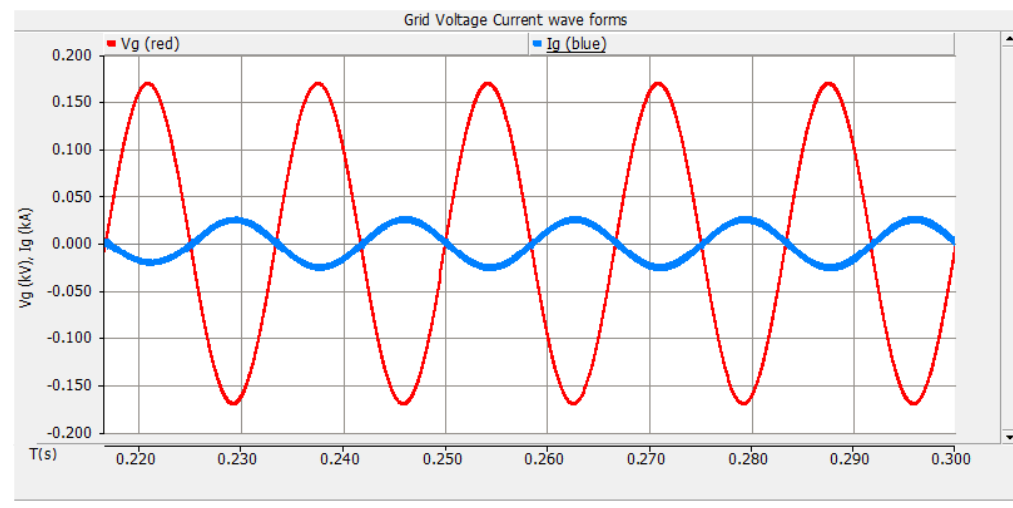

(a)

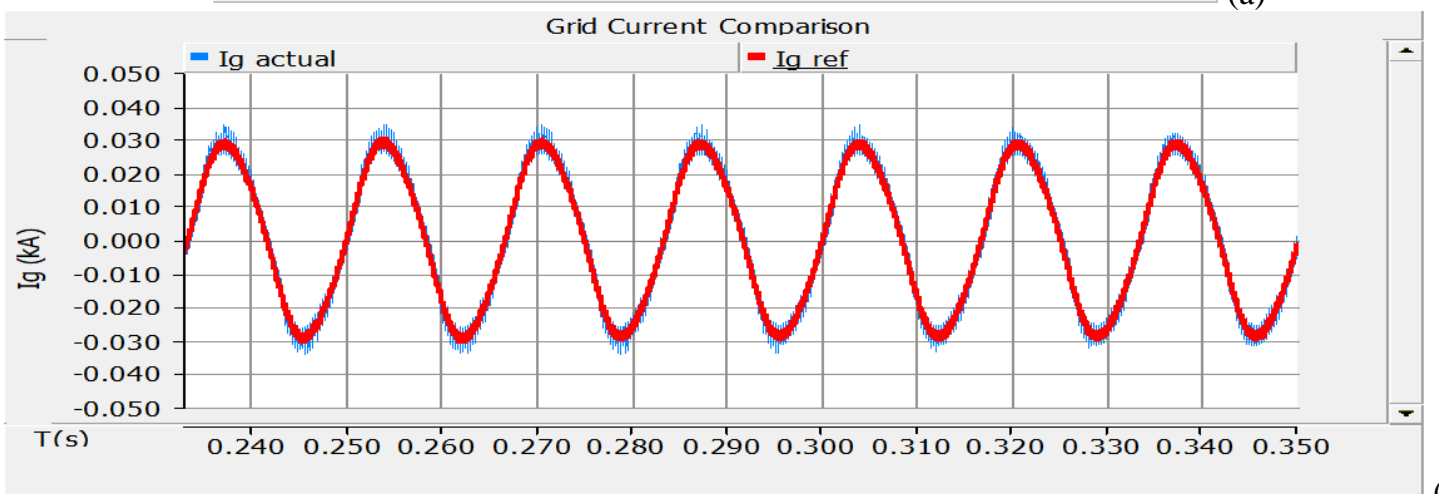

(b)

Figure 27. (a) Grid Voltage and Current during discharging (b) Grid Current tracking during discharging.
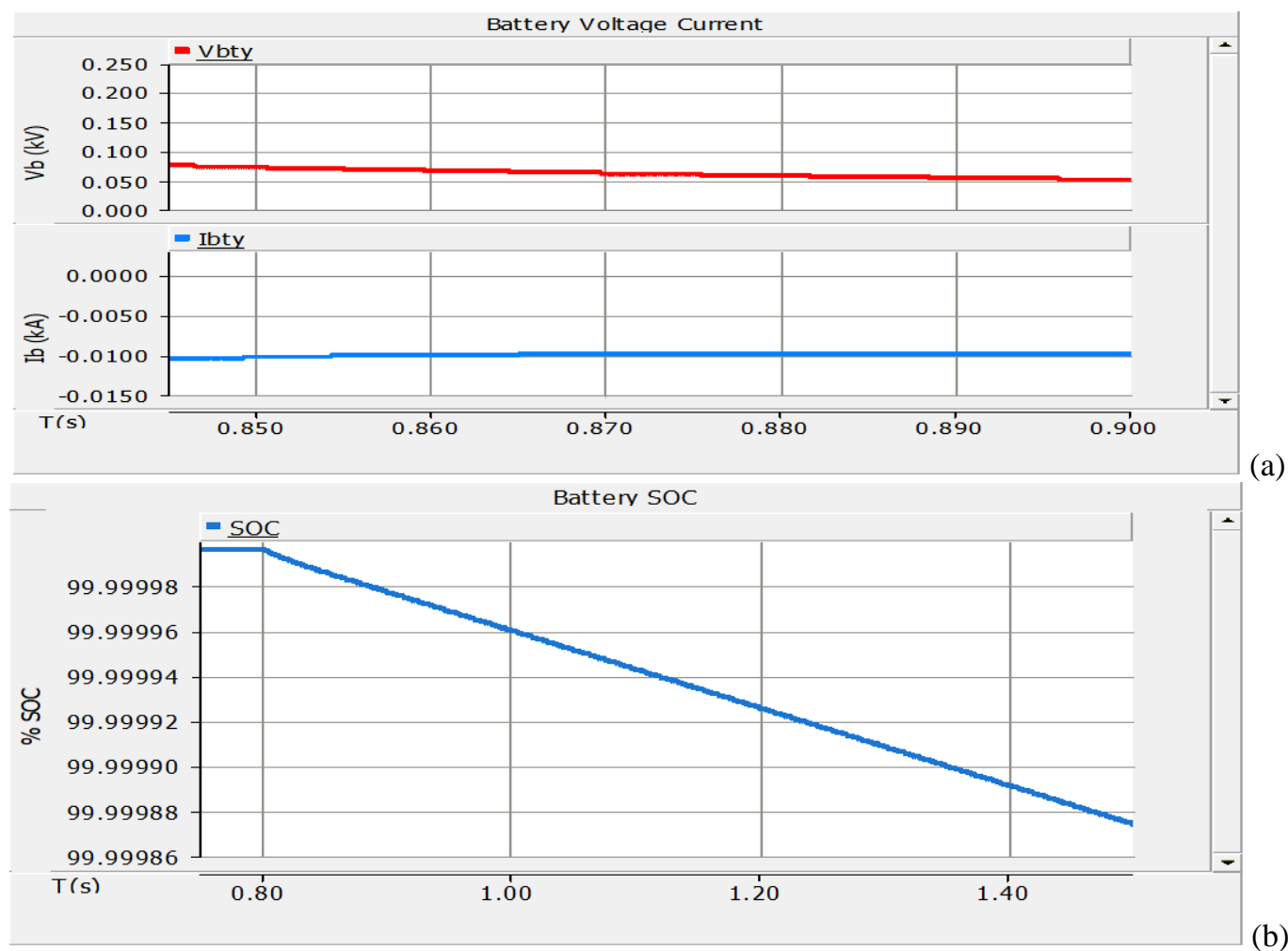

Figure 28. (a) Battery Voltage and Current, (b) Battery State of Charge during discharging. 


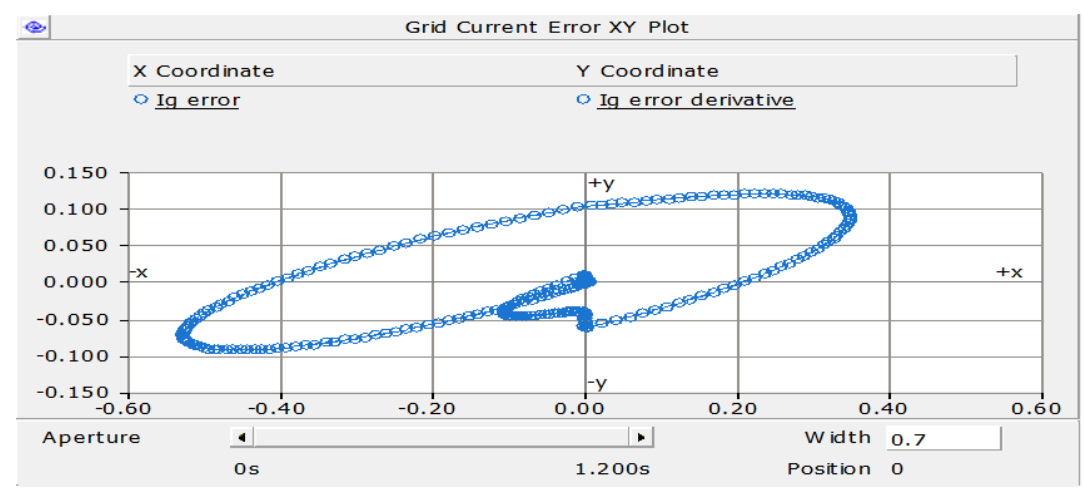

Figure 29. Phase plot of grid current.

During discharging, the battery current and voltage waveforms are shown in Fig. 28(a) with decreasing voltage the current waveform remaining constant. Fig. 28(b) shows the battery state of charge during discharging [11]. Fig. 29 shows the phase plot of SMC for convergence. It is seen that the desired variable is reaching the origin within a small settling time and the system is said to be in stable operation.

\subsubsection{Reactive power support to Grid}

The on-board chargers can be effective for reactive power support during discharging mode. It does not affect the battery SOC. Only the dc link capacitor may wear out due to frequent charging and discharging cycles. In this work, reactive power support of EV is discussed. It is assumed that the EV requires full charging during peak load hours and is connected to the grid at this instant. The simulation starts from the charging instant. Now when once EV's are connected, the voltages at the buses decrease and the active and reactive power consumption at the residential rises [12-13].

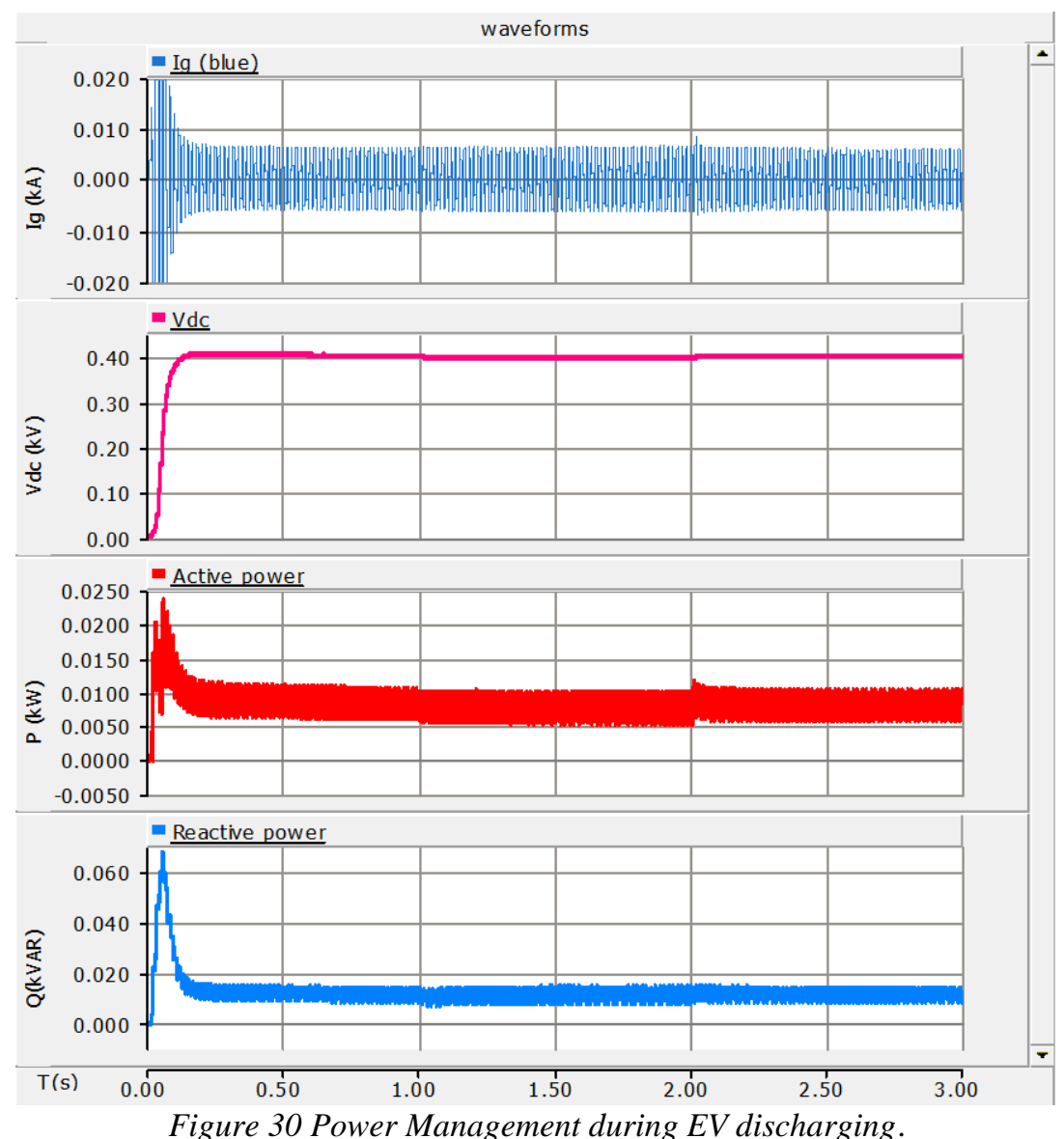


The utility has to compensate this voltage drop at the buses. Hence reactive power support is required. A simulation platform for less duration (0-3s) is created as the discharging time is large during V2G mode of operation. Fig. 30 shows the waveforms which is explained quantitatively in Table 6.

Table 6. Active and Reactive Powers during Discharging

\begin{tabular}{ccccc} 
Time $(\mathrm{sec})$ & Active power $(\mathrm{kW})$ & Reactive power $(\mathrm{kVAR})$ & DC Voltage (Volts) & Power factor \\
\hline $0-1$ & 11 & 15.1 & 403 & $0.8 \mathrm{Lag}$ \\
$1-2$ & 10 & 13.7 & 397.5 & $0.6 \mathrm{Lead}$ \\
$2-3$ & 11.5 & 15.3 & 403 & Unity \\
\hline
\end{tabular}

The charging current remains unchanged during the transitions from lagging to unity power factor. It is clear from Fig. 29, the EV supports reactive power with very less variations in the dc link voltage. Further work can be carried out in this part.

\section{SOLAR BASED ELECTRIC VEHICLE CHARGING}

Solar Energy can be utilized for EV applications in urban areas. Hence the burden on the grid gets reduced when EV's are directly integrated to the solar charging stations [14]. Therefore, in this section, electric vehicle charging with solar PV array is proposed.

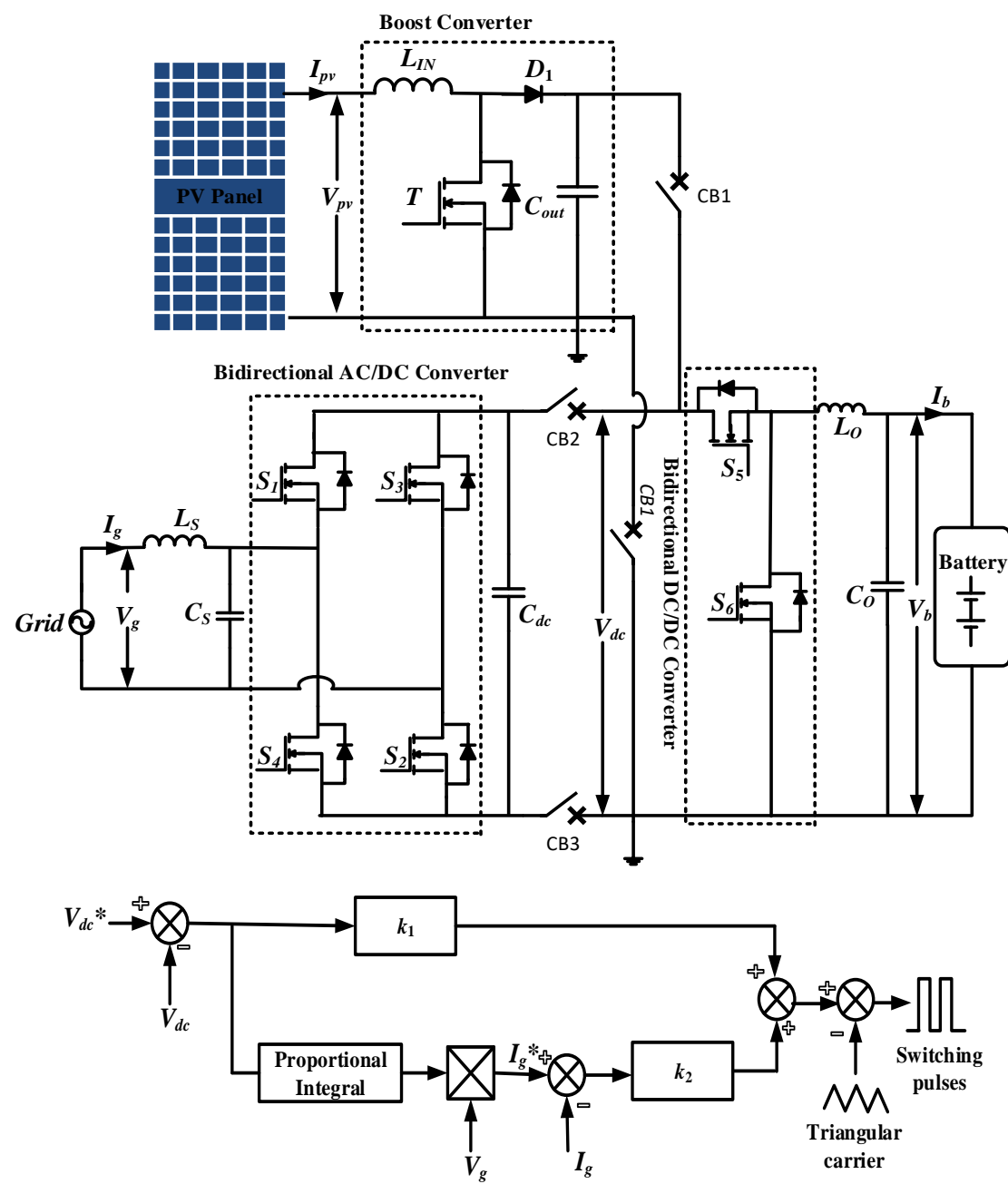

(a)

Figure 31(a) Solar PV based Electric Vehicle Charging, (b) Boost Converter Control Circuit. 
Fig. 31 (a) shows the electric vehicle charging with grid as well as with the solar PV [15-18]. In the day time the power generated by the solar PV is utilized to charge electric vehicle. When solar power is not available, the electric vehicle is charged with the power grid. Fig 31(b) shows the SMC controller used for the PV boost converter. PV array is operated with $1000 \mathrm{~W} / \mathrm{m}^{2}$ solar irradiance and at $25^{\circ} \mathrm{C}$. The open circuit (OC) voltage and short circuit (SC) current for the MPPT are $220 \mathrm{~V}$ and 2.5 A respectively [1920]. Three Circuit breakers (CB1, CB2 and CB3) are used in the simulation work for obtaining the desired mode of operation using SMC in this circuit.

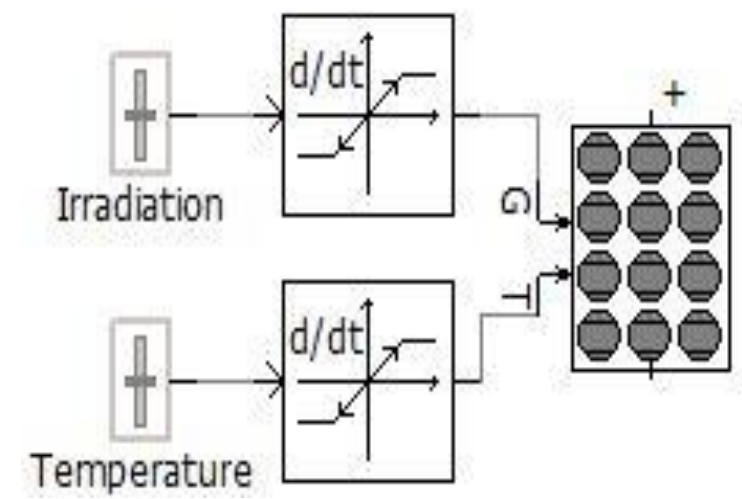

Figure 32. PV panel with input labels.

Table 7 PV Panel Parameters

\begin{tabular}{lr}
\hline \multicolumn{1}{c}{ PV Array Parameters } & Value \\
\hline Number of modules connected in series per array & 7 \\
Number of module strings in parallel per array & 10 \\
Number of cells connected in series per module & 36 \\
Number of cell strings in parallel per module & 1 \\
Reference irradiation & 1000 \\
Reference cell temperature & 25 \\
\hline
\end{tabular}

Table 8 Boost Converter Parameters

\begin{tabular}{ll}
\hline Parameters & Value \\
\hline Input Voltage & $200 \mathrm{~V}$ \\
Output Voltage & $400 \mathrm{~V}$ \\
Input inductor, $\mathrm{L}_{\mathrm{IN}}$ & $1.3 \mathrm{mH}$ \\
Output capacitor, $\mathrm{C}_{\text {out }}$ & $2500 \mu \mathrm{F}$ \\
Duty ratio & 0.5 \\
Switching frequency & $15 \mathrm{kHz}$ \\
SMC Controller parameters $K_{1}, K_{2}$ & 1000,10 \\
\hline
\end{tabular}

Fig. 32 shows the PV panel with input labels used in the software. Table 7 shows the PV panel parameters used in this work. Table 8 shows Boost converter design parameters used for simulation. Fig. 33(a) shows the switching pulses obtained for the solar PV boost converter. Fig. 33(b) shows the switching pulses obtained for a buck converter during charging mode. Fig. 34(a) shows I-V and P-V array characteristics of the solar panel. The PV array and MPPT voltage tracking [21-22] are shown in Fig. 34(b). The PV array takes $0.122 \mathrm{~s}$ time to follow the MPPT reference voltage $\left(V_{\text {mppt }}\right)$ and the error during steady state is observed to be $0.5 \%$. Fig. 35(a) shows the obtained boost converter output voltage 400V. 


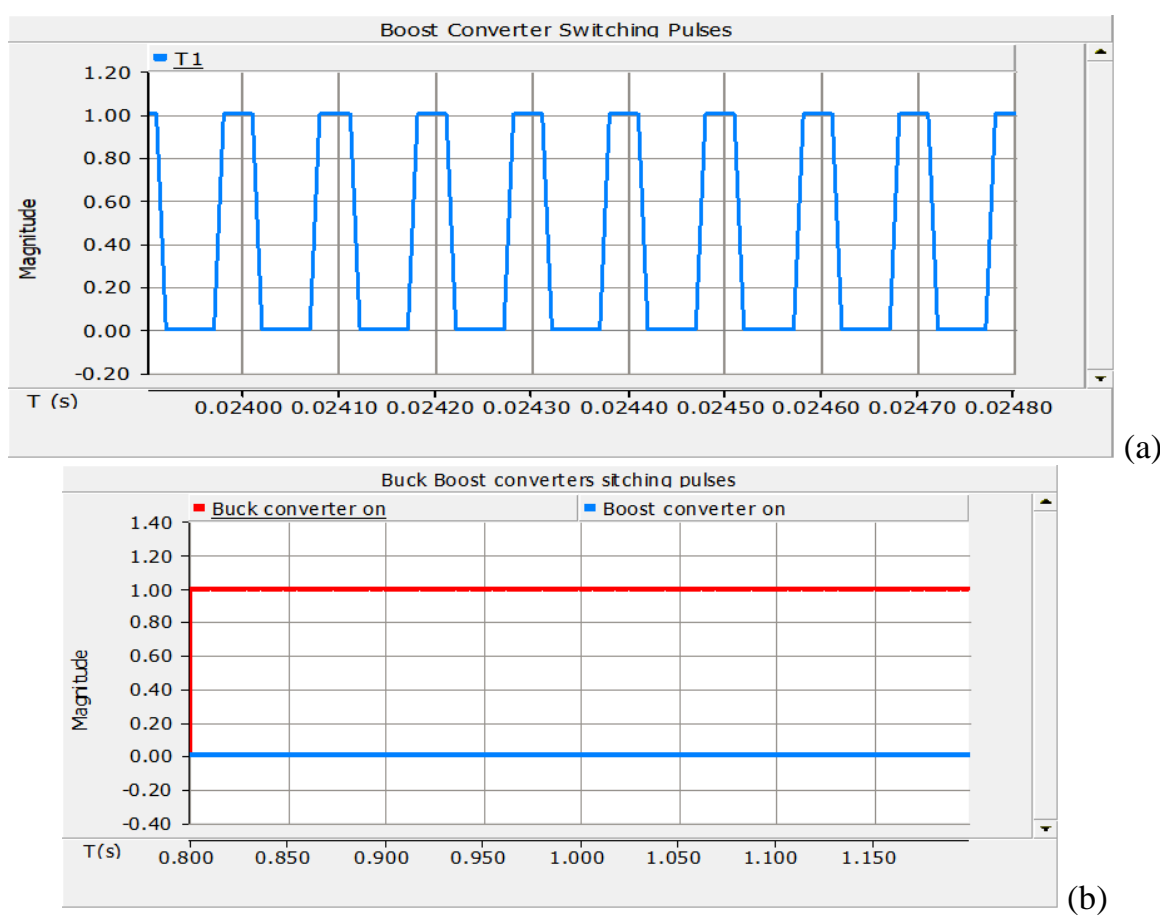

Figure 33. Boost Converter Switching Pulses, (b) Buck Converter Switching Pulses.

The battery current and voltage are shown in Fig. 35(b). During EV solar charging, the battery state of charge [23] is shown in Fig. 35(c). Upto $2 \mathrm{~s}$ grid charges the electric vehicle and after $2 \mathrm{~s}$ the solar energy charges the electric vehicle, it takes few seconds to settle as shown in Fig. 35(d). It is observed that the electric vehicle is charged $100 \%$ with solar PV within a short period. The authors would like to emphasis that the simulation was performed only to realize the controller's performance and hence charging was done only for a short period it takes number of hours as it is known.

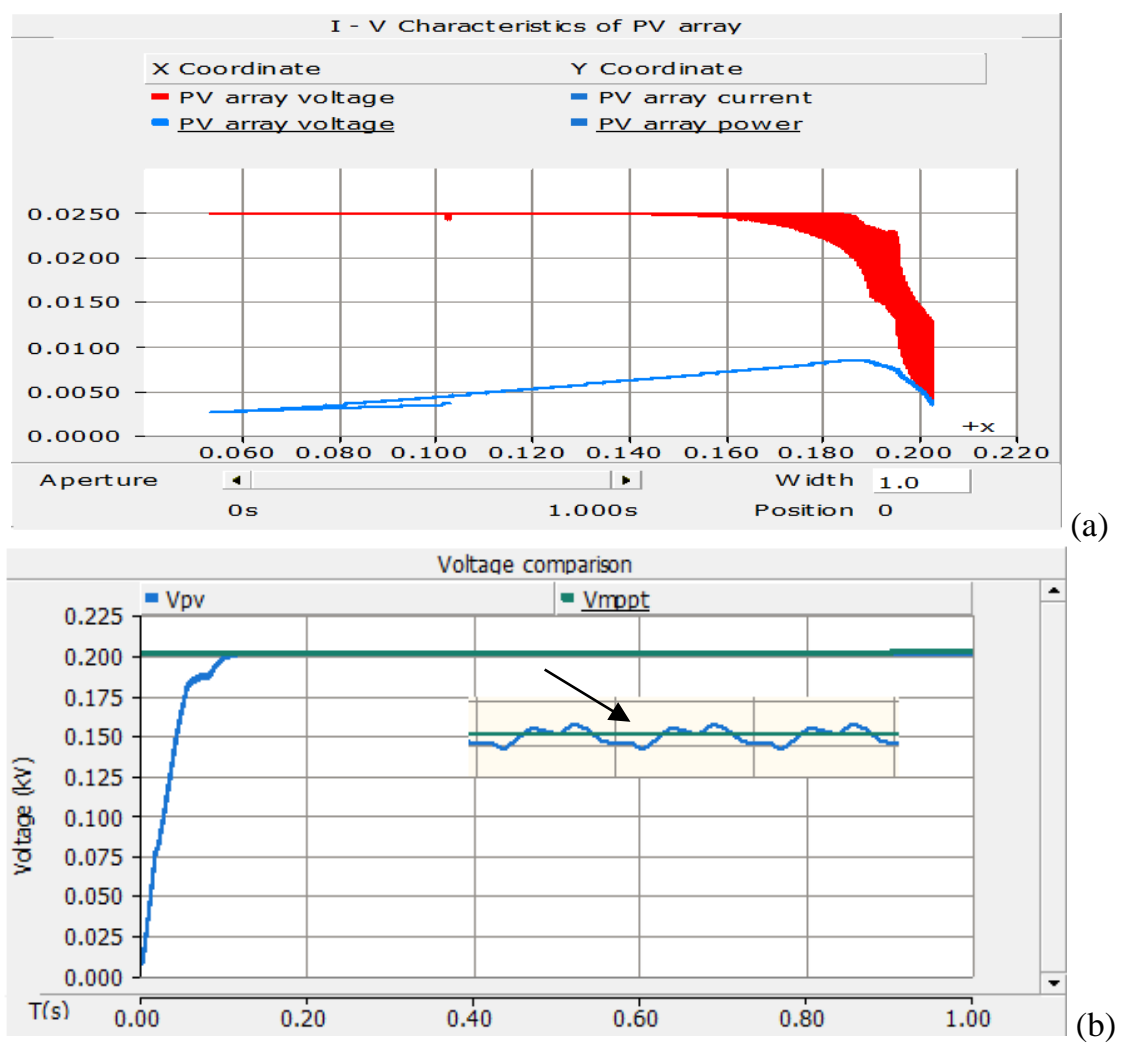

Figure 34(a). I-V and P-V characteristics (b) Tracking of MPPT and $V_{p v}$ voltage. 


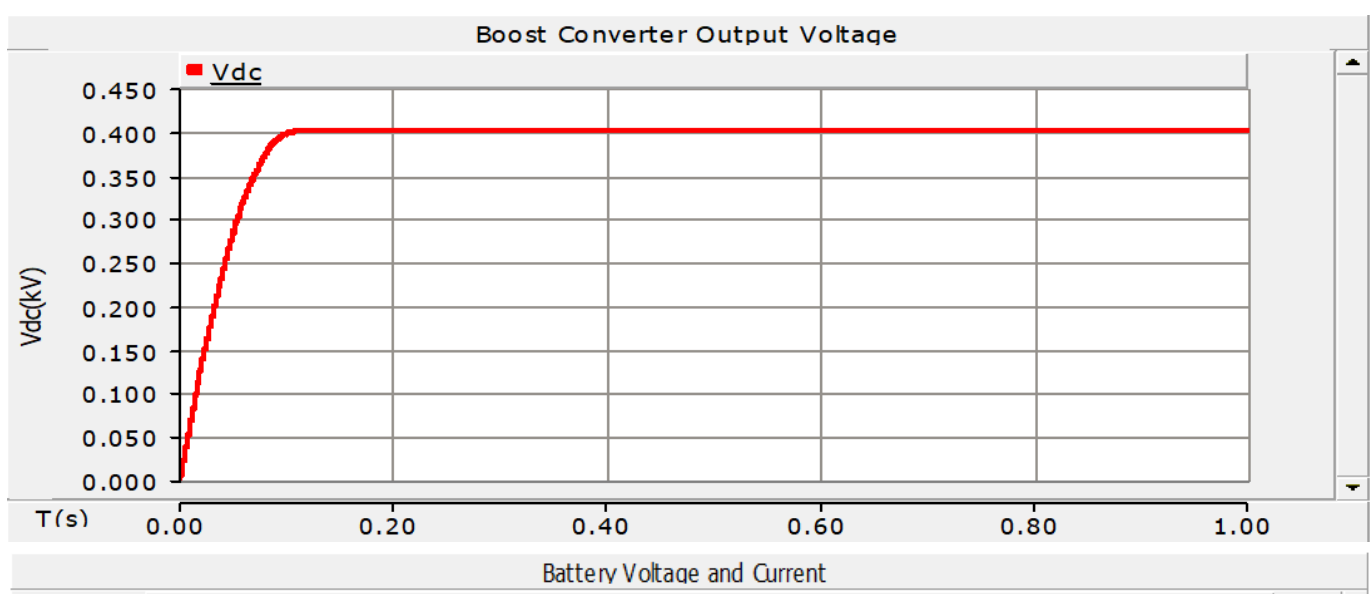

(a)
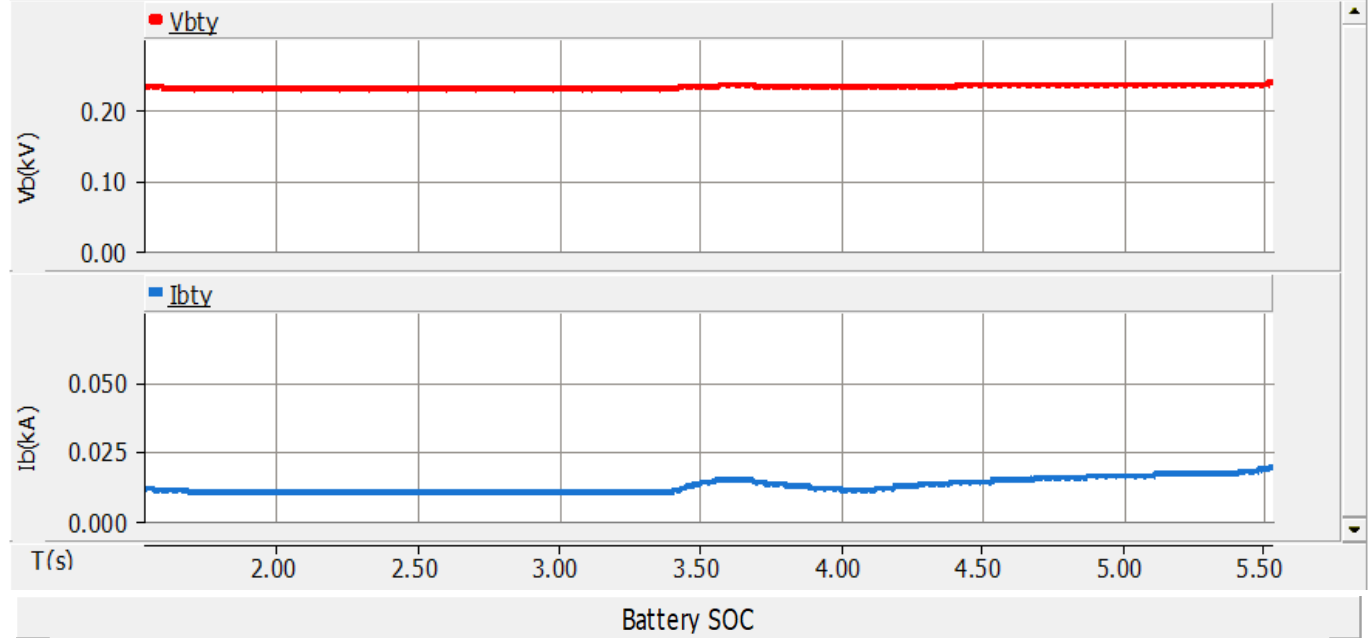

(b)
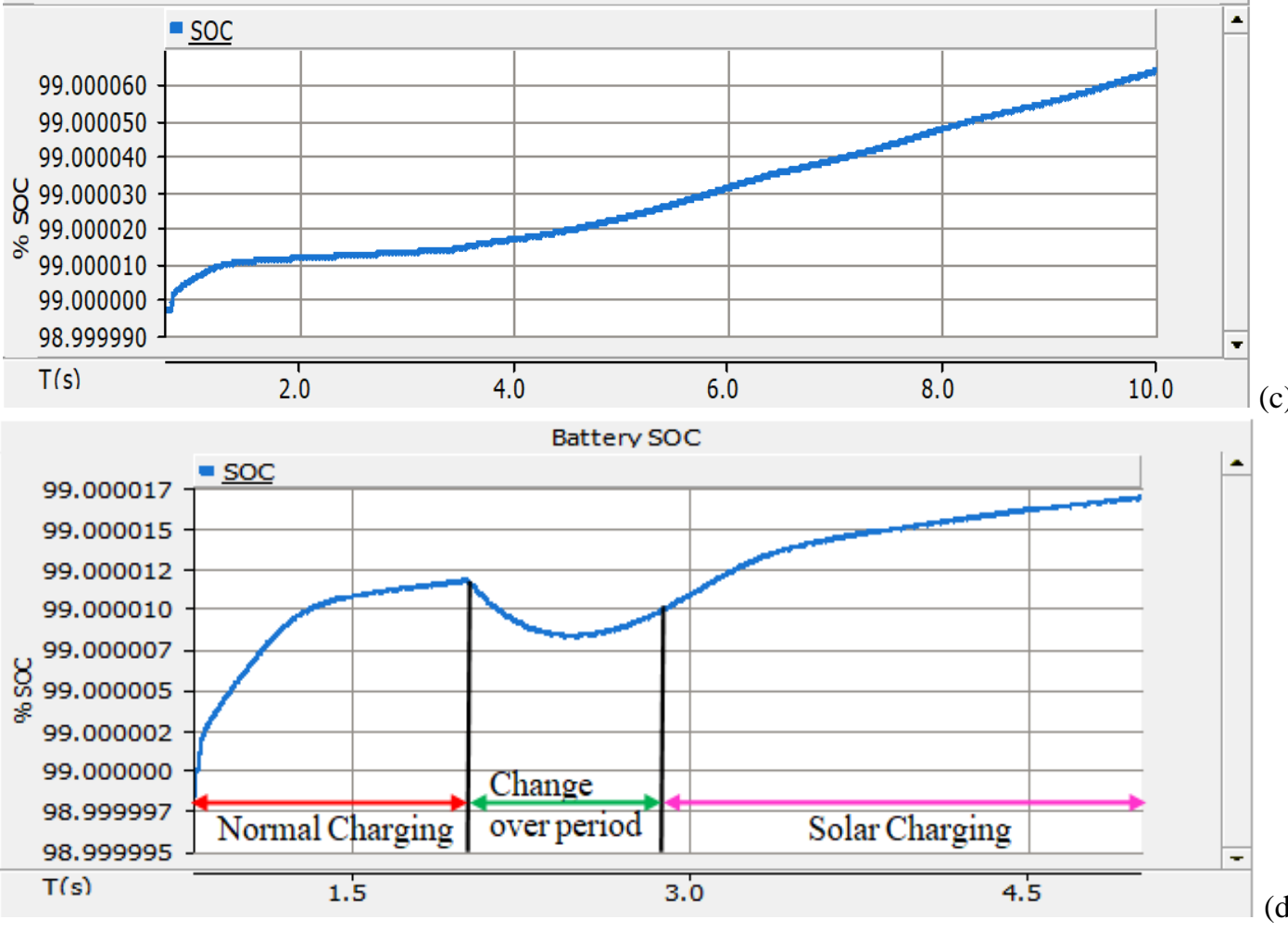

(d)

Figure 35 (a) Boost Converter Output Voltage, (b) Battery Voltage and Current during charging, (c) Battery State of Charge during charging, (d) Battery SOC during Grid and Solar charging. 


\section{CONCLUSIONS AND FUTURE SCOPE OF WORK}

A $2.5 \mathrm{~kW}-5 \mathrm{~kW}$ battery charger with $100 \mathrm{Ah}$ capacity is used in a single phase $120 \mathrm{~V} \mathrm{rms}, 60 \mathrm{~Hz} \mathrm{EV}$ configuration system. A bidirectional AC/DC and a bidirectional DC/DC converter work as power modulators between the source and the battery. G2V (charging) and V2G (discharging) mode are obtained individually and also in a single stage conversion from the proposed EV circuit configuration using SMC. The system stability obtained has good stability margins using frequency response plots derived from state feedback approach. SMC is found to track the DC voltage and grid current effectively with less steady state error of $1.52 \%$. It is found that THD in grid current is $0.645 \%$ during G2V and $1.95 \%$ in V2G which are within the IEEE standards. The system is said to converge to origin within 0.1 $\mathrm{s}$ and is presented through a phase plane. It is also found to be robust during grid frequency variations. As compared to conventional PI and PR controllers, better performance of SMC is realized. The SOC of the battery is not affected during the operation of reactive power support to the grid is studied. The authors have presented also a solar based EV charging circuit as an extension to the work. The simulation results obtained are found to be good in charging the battery to $100 \%$ with its rated voltage within a short period of time. A solar based on-board charger at homes gives more flexibility to the user for charging and during time of power failures.

The future scope lies in using other different SMC available in literature such as fast terminal for finite time convergence, higher order SMC for reducing chattering, etc., for solar based EV charging which has a promising future. The burden on the grid gets reduced when EV's are directly integrated to the solar charging stations. Hence research in this direction is well understood through this work.

\section{REFERENCES}

[1] Ehsani, M., Gao, Y., Gay, Sebastien, E, Emadi, A. modern electric, hybrid electric, and fuel cell vehicles fundamentals, theory, and design, $2^{\text {nd }}$ edition. Boca Raton, London, New York, Washington D.C: CRC PRESS, 2005.

[2] Yilmaz, M., Krein, P.T., Review of battery charger topologies,charging power levels and infrastructure for plug-in electric and hybrid vehicles. IEEE Transactions on Power Electronics, 2013, 28(5), 2151-2169, DOI:10.1109/TPEL.2012.2212917.

[3] Zhou, X., Lukic, S., Bhattacharya, S., Huang, A., Design and control of grid-connected converter in Bidirectional battery charger for plugin hybrid electric vehicle application, Proc. IEEE Veh. Power and Propulsion Conf.( 7-10 Sept. 2009, Dearborn, MI, USA), 2009, 1716-1721, DOI:10.1109/VPPC.2009.5289691.

[4] Roshini, S., Ashok, Y., Shtessel, B., Malek, G., Sliding Mode Control of Hydrogen Fuel Cell and Ultra capacitor Based Electric Power System: Electric Vehicle Application, IFAC-Papers OnLine, 2017, 50 (1), 14794-14799, ELSEVIER, DOI: 10.1016/j.ifacol.2017.08.2552.

[5] Song, Z., Hou, J., Hofmann, H., Jianqiu, L., Ouyang, M., Sliding-mode and Lyapunov function-based control for battery/supercapacitor hybrid energy storage system used in electric vehicles, Energy, 2017, 122, 601-612, ELSEVIER, DOI: 122. 10.1016/j.energy.2017.01.098.

[6] Wang, B., Xu, J., Xu, D. Yan, Z., Implementation of an estimator-based adaptive sliding mode control strategy for a boost converter based battery/supercapacitor hybrid energy storage system in electric vehicles, Energy Conversion and management, 2017, 151, 562-572, ELSEVIER, DOI: 10.1016/j.enconman.2017.09.007.

[7] Komurcugil, H., Ozdemir, S., Sefa, I., Altin, N., Kukrer, O., Sliding-Mode Control for Single-Phase GridConnected LCL-Filtered VSI With Double-Band Hysteresis Scheme, IEEE Transactions on Industrial Electronics, 2016, 63(2), 864-873, DOI:10.1109/TIE.2015.2477486.

[8] Gudey, S.K., Rajesh Gupta, R., Sliding mode control in voltage source inverter-based higher-order circuits. International Journal of Electronics, 2015, 102(4), 668-689, https://doi.org/10.1080/00207217.2014.936523

[9] Kumar, S., Usman, A., A review of converter topologies for battery applications in plug-in hybrid electric vehicles, IEEE Industry Applications Society Annual Meeting (IAS), (23-27 Sept. 2018: Portland, OR, USA), 2018, 1-9, DOI: 10.1109/IAS.2018.8544609. 
[10] Monteiro, V., Pinto, J.G., Afonso, J.L., Operation modes for the electric vehicle in smart grids and smart homes: Present and proposed modes. IEEE Trans.Veh. Technol., 2016, 65(3), 1007-1020, DOI:10.1109/TVT.2015.2481005

[11] Zhou, X., Wang, G., Lukic, S., Bhattacharya, S., Huang, A., Multi- function bi-directional battery charger for plug-in hybrid electrical vehicle application, IEEE Energy Conversion Congress and Exposition (25-27 Sept. 2009: San Jose, CA, USA), 2009, 3930-3936. DOI:10.1109/ECCE.2009.5316226

[12] Kisacikoglu, M,C, Ozpineci, B, Tolbert, L.M., EV/PHEV bidirectional charger assessment for V2G reactive power operation, IEEE Trans. Power Electron., 2013, 28(12), 5717-5727, DOI:10.1109/TPEL.2013.2251007.

[13] Monteiro, V., Pinto, J.G., Exposto, B., Henrique Goncalves, Ferreira, Joao C, Carlos Couto, Afonso Joao L., Assessment of a battery charger for Electric Vehicles with reactive power control, IECON-38 $8^{\text {th }}$ Annual Conference on IEEE Industrial Electronics Society(25-28 Oct. 2012, Montreal, Canada, QC), 5142-5147, DOI: 10.1109/IECON.2012.6389554

[14] Liu, N., Chen, Q., Lu, X., Liu, J., Zhang, J., A charging strategy for PV-based battery switch station considering service availability and self-consumption of PV energy, IEEE Trans. Ind Electronics., 2015, 62(8), 4878-4889, DOI:10.1109/TIE.2015.2404316.

[15] Chaudhari, K., Ukil, A., Kumar, K.N., Manandhar, U., Kollimalla, S.K., Hybrid optimization for economic deployment of ESS in PV-integrated EV charging stations, IEEE Trans. Ind. Informat., 2018, 14(1), 106-116, DOI: 10.1109/TII.2017.2713481.

[16] Singh, B., Verma, A., Chandra, A., Al-Haddad, K., Implementation of solar PV- battery and diesel generator based electric vehicle charging station, IEEE International Conference on Power Electronics, Drives and Energy Systems (PEDES, 18-21 Dec. 2018, Chennai, India), 2018, 1-6, DOI:10.1109/PEDES.2018.8707673

[17] Nguyen, H., N.T., Zhang, C., Zhang, J., Dynamic demand control of electric vehicles to support power grid with high penetration level of renewable energy, IEEE Trans. Transportation Electrification, 2016, 2(1), 6675, DOI:10.1109/TTE.2016.2519821.

[18] Ma, T., Mohammed, O.A., Optimal charging of plug-in electric vehicles for a car-park infrastructure, IEEE Trans. Industry Applications, 2014, 50(4), 2323-2330, DOI: 10.1109/IAS.2012.6374035.

[19] Sah, B., Kumar, G.V.E.S., A comparative study of different MPPT techniques using different dc-dc converters in a standalone PV system, IEEE TENCON (22-25 Nov 2016, Singapore), 2016, 1690-1695, DOI: 10.1109/TENCON.2016.7848306.

[20] Sabanc1, K., Balc1, S., Aslan, M.F., Estimation of switching losses in DC-DC boost converters by various machine learning methods, Journal of Energy Systems, 2020, 4(1), 1-11, https://doi.org/10.30521/jes.635582

[21] Madzharov, N.D., Tonchev, A.T., Inductive high power transfer technologies for electric vehicles, Journal of Electrical Engineering, 2014, 65(2), 125-128, DOI: 10.2478/jee-2014-0019.

[22] Tabti, K., Bourahla M., Mostefai, L., Hybrid control of electric vehicle lateral dynamics stabilization, Journal of Electrical Engineering, 2013, 64, 50-54, DOI: 10.2478/jee-2013-0007.

[23] Paudyal, S., Ceylan, O., Battarai, B. P., Meyers K.S., Optimal coordinated EV charging with reactive power support in constrained distribution grids, IEEE Power and Energy Society General meeting (16-20 July 2017, Chicago, USA), 2017, 1-6, DOI: 10.1109/PESGM.2017.8274266. 